\title{
Parents' Perspectives, Observations, and Interpretations of: Cancer-Related Fatigue and How the Symptom Shapes their Child's Day-to-Day Quality of Life
}

\author{
Tina Antill Keener \\ West Virginia University
}

Follow this and additional works at: https://researchrepository.wvu.edu/etd

\footnotetext{
Recommended Citation

Keener, Tina Antill, "Parents' Perspectives, Observations, and Interpretations of: Cancer-Related Fatigue and How the Symptom Shapes their Child's Day-to-Day Quality of Life" (2013). Graduate Theses, Dissertations, and Problem Reports. 3646.

https://researchrepository.wvu.edu/etd/3646

This Dissertation is protected by copyright and/or related rights. It has been brought to you by the The Research Repository @ WVU with permission from the rights-holder(s). You are free to use this Dissertation in any way that is permitted by the copyright and related rights legislation that applies to your use. For other uses you must obtain permission from the rights-holder(s) directly, unless additional rights are indicated by a Creative Commons license in the record and/ or on the work itself. This Dissertation has been accepted for inclusion in WVU Graduate Theses, Dissertations, and Problem Reports collection by an authorized administrator of The Research Repository @ WVU. For more information, please contact researchrepository@mail.wvu.edu.
} 
Parents' Perspectives, Observations, and Interpretations of: Cancer-Related Fatigue and How the Symptom Shapes their Child's Day-to-Day Quality of Life

\title{
Tina Antill Keener
}

Dissertation submitted to the

School of Nursing

at West Virginia University

In partial fulfillment of the requirements

for the degree of

\author{
Doctor of Philosophy \\ in \\ Nursing
}

\author{
Dr. Joy Buck PhD, RN \\ Dr. Margaret Burkhardt PhD, RN \\ Dr. Pamela Hinds PhD, RN, FAAN \\ Dr. Marilyn Smith PhD, RN \\ Dr. Mary Jane Smith PhD, RN \\ Department of Nursing
}

Morgantown, West Virginia

2013

Keywords: Cancer-Related Fatigue; Children; Qualitative Description; Content Analysis Copyright 2013 Tina Antill Keener 


\section{ABSTRACT \\ Parents' Perspectives, Observations, and Interpretations of: Cancer-Related Fatigue and How the Symptom Shapes their Child's Day-to-Day Quality of Life}

Tina Antill Keener

Fatigue is a common and distressing symptom of childhood cancer that is often viewed as an inevitable part of cancer treatment and under assessed in clinical practice. Yet, cancer-related fatigue can disrupt normal childhood development and family functioning, as well as, signal serious complications of cancer and its treatment. Little is known about fatigue and quality of life among children undergoing cancer treatment in outpatient settings. This qualitative descriptive study explored parents' observations and interpretations of cancer-related fatigue and how it shaped their child's day-to-day quality of life during cancer treatment. Eleven participant interviews were gathered from parents of children (1-12 years of age). Data collection and analysis were guided by the concept of pediatric cancer-related fatigue, domains of pediatric quality of life, and methods of conventional content analysis. Three themes containing 7 categories and subcategories emerged that represented parents' descriptions and interpretations of (a) life before cancer diagnosis, (b) fatigue shaping everyday quality of life, and (c) perspectives on fatigue. Participants noted changes in their child's life before and after cancer and described behavioral manifestations of fatigue disrupting relationships with siblings and peers, school attendance, play and participation in preferred activities, family outings and functioning, and other domains of quality of life. However, the parents did not interpret or attribute these changes to the symptom of fatigue shaping everyday quality of life. The findings of this study suggest that parents of children with cancer and health professionals have different definitions, perspectives, and interpretations of the meaning of cancer-related fatigue to a child's everyday quality of life. Implications for nursing practice, theory, research, and education are discussed. 


\section{Dedication}

This dissertation is dedicated to my husband George and two children, Geo and Max.

This manuscript is a product of their support and patience. Additionally, I dedicate this dissertation to my parents who always believed in my dreams. 


\section{Acknowledgements}

This work could not have been completed without the support of several important people. First and foremost, I would like to express my deepest appreciation to my committee members Dr. Joy Buck, Dr. Margaret Burkhardt, Dr. Pamela Hinds, Dr. Marilyn Smith, and Dr. Mary Jane Smith. I thank you for good support and guidance throughout this endeavor. A special thanks to my committee chair, Dr. Joy Buck. Your encouragement and support were pivotal in my success, especially during many personal challenges encountered throughout my dissertation journey.

I would like to thank my friends and family members who waited patiently for this work to be completed and provided so much support along the way. A special thanks to Sara and Margaret, few understand the triumphs and sorrows associated with doctoral education. Thank you for "getting it" and picking me up when I fell. To my best friend Lisa, I could not have done this without your friendship. Our friendship is my "safe haven," the place I turn for support and comic relief. To my parents, who always believed in me and encouraged me to make my own choices (and sometimes mistakes). Lastly but certainly not least, my husband and two boys, thank you for your patience. I hope my time can now become "our time." 


\section{Table of Contents}

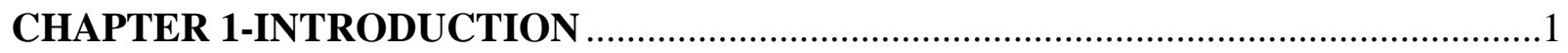

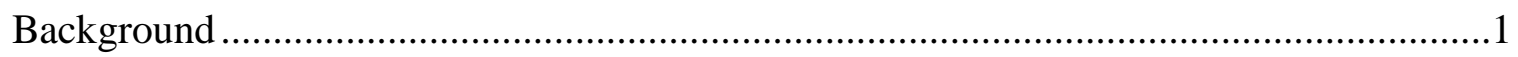

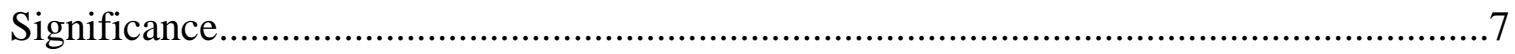

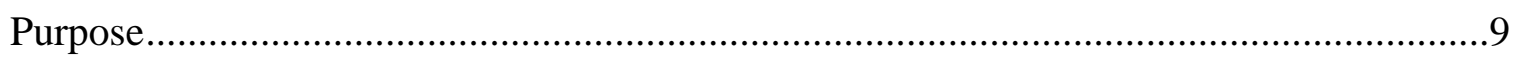

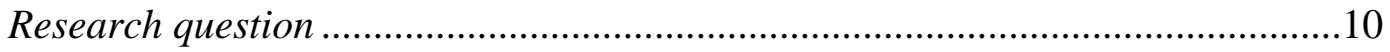

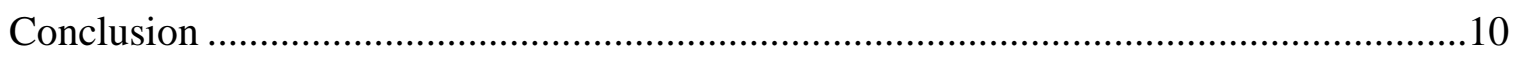

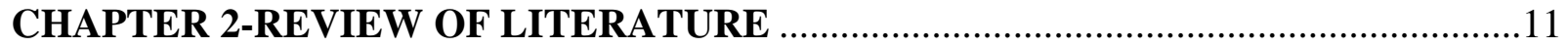

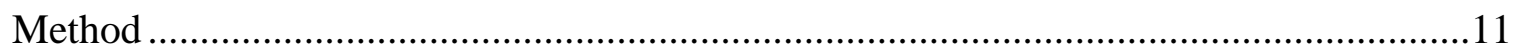

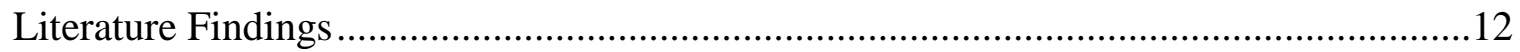

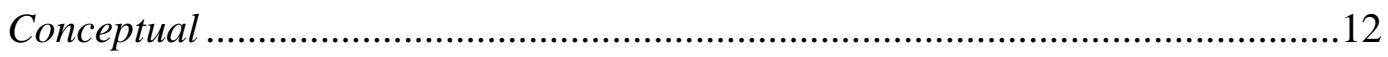

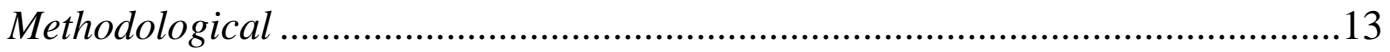

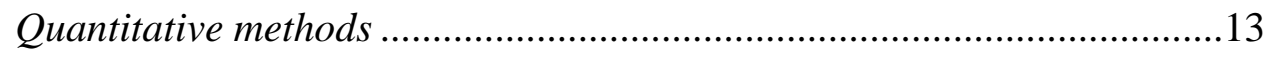

Qualitative methods ...................................................................... 15

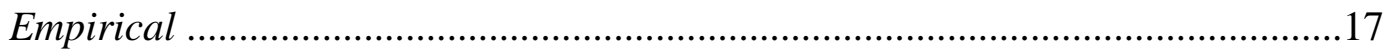

Physical, mental, and emotional symptoms ........................................17

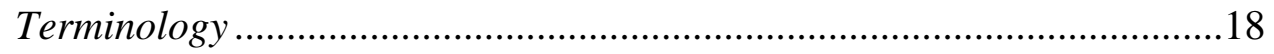

Causes and alleviating factors ...................................................... 18

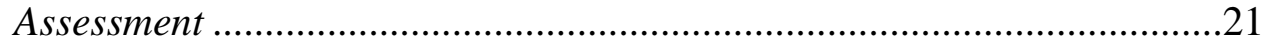

Effect on lifestyle and family system ................................................22

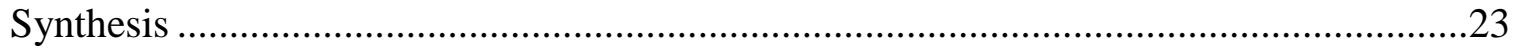

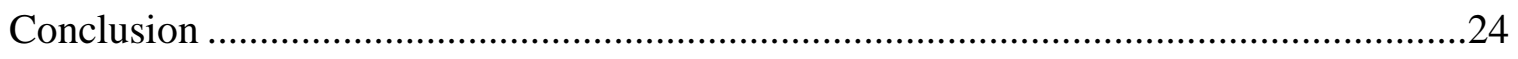

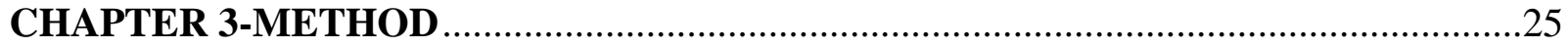




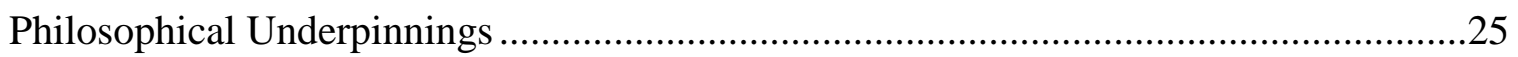

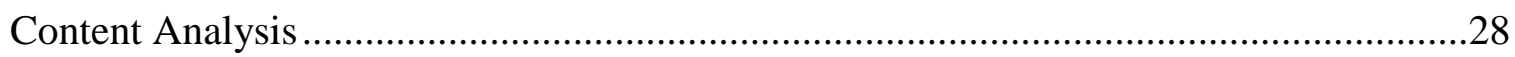

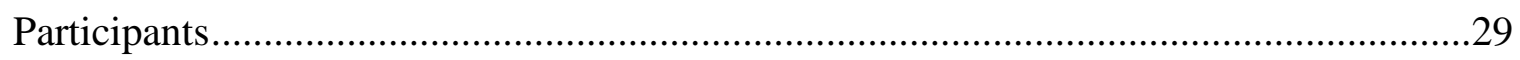

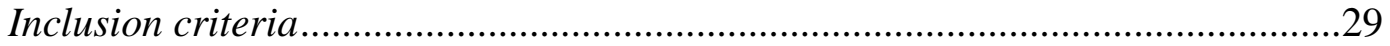

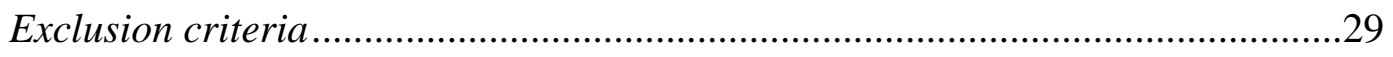

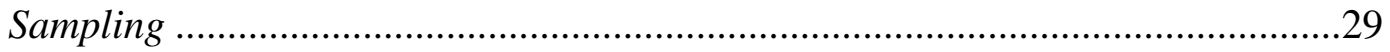

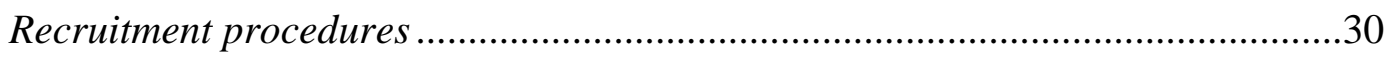

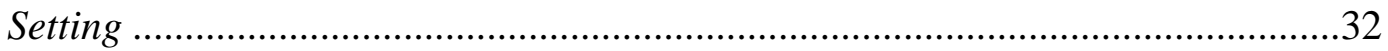

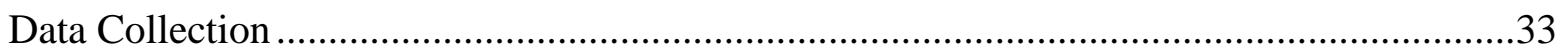

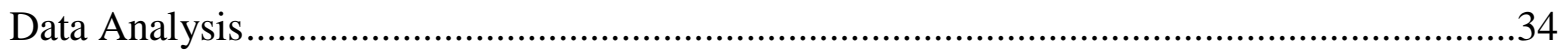

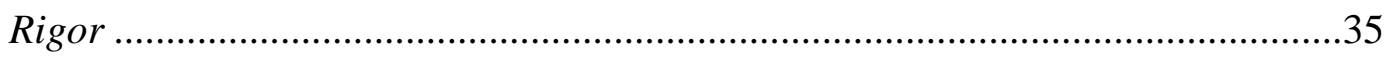

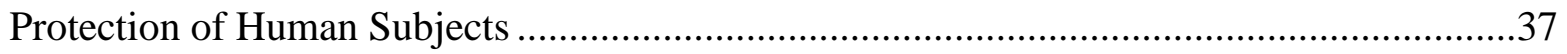

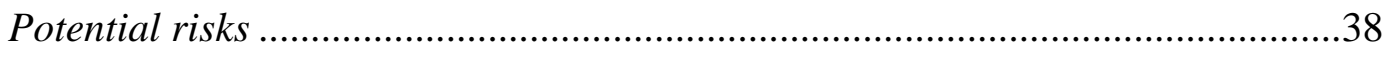

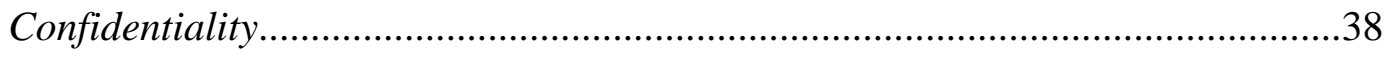

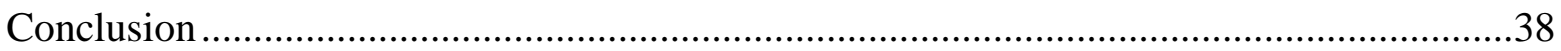

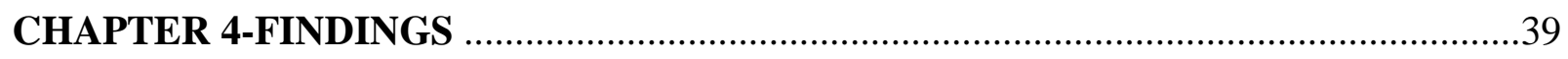

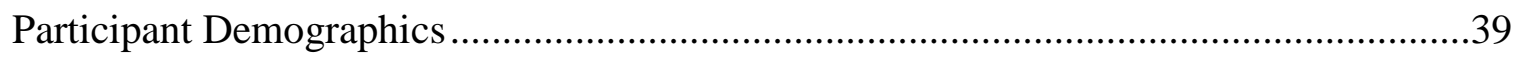

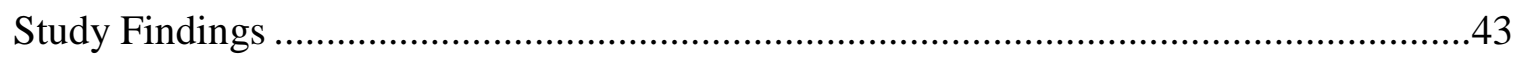

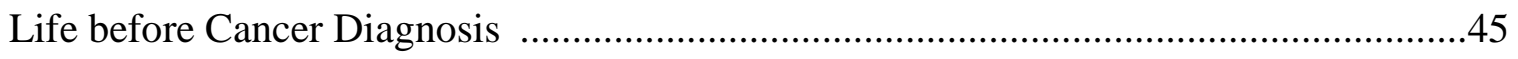

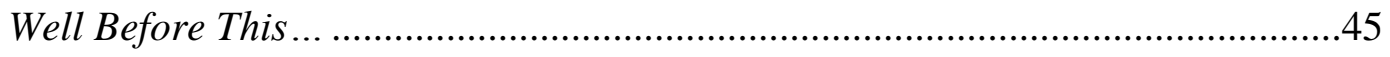

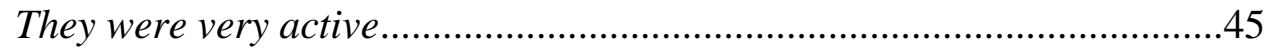

They enjoyed playing with other kids ..................................................45

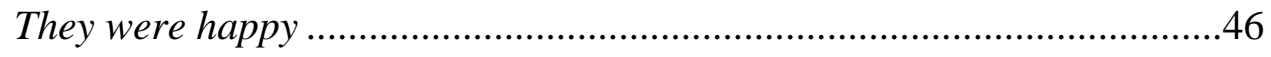




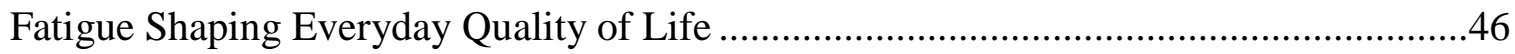

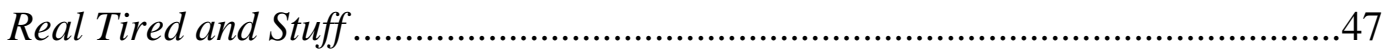

There are days they just lay around ....................................................48

Sleeps A Lot and That's Not Normal ..............................................................48

At times they completely shut down ..................................................49

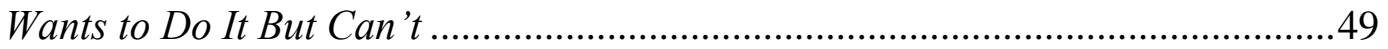

They aren 't as active .....................................................................50

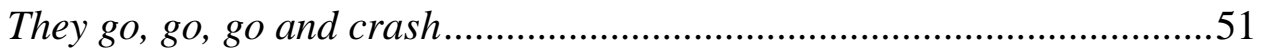

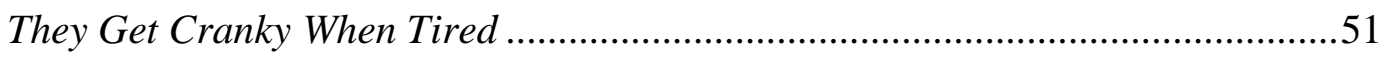

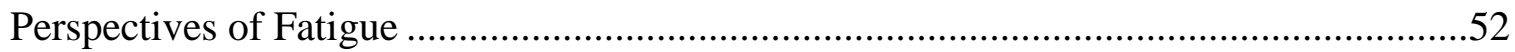

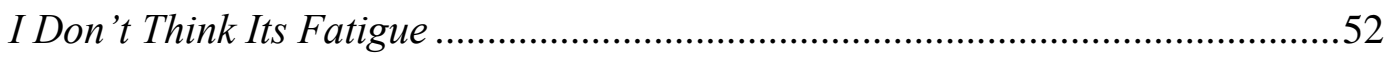

I'm Sure Treatment Has A Lot to Do With It .....................................................54

Steroids are the worst ........................................................................55

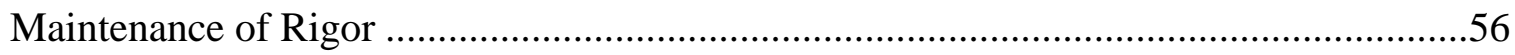

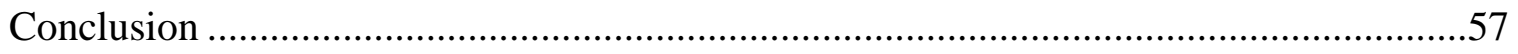

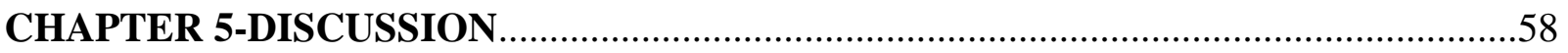

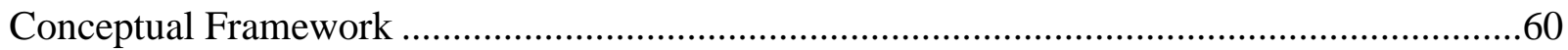

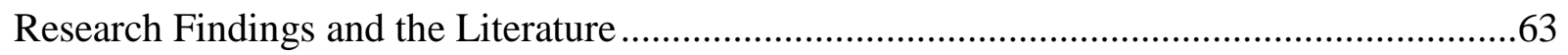

Differences exist in how parents, researchers, and clinicians talk about childhood cancerrelated fatigue and make sense of how the symptom shapes the child's day-to-day quality

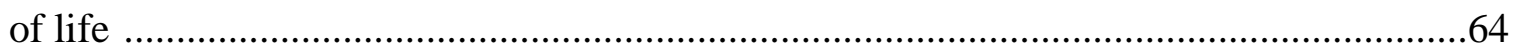

Parents find it difficult to "deconstruct” their child's symptom experiences .......64

Parents develop a "new normal" for their child with cancer .............................65 
Fatigue and/or quality of life represent something much different to parents than the researcher

Parents of very young children $(<3$ years of age; $n=2$ ) describes different characteristics and manifestations of fatigue

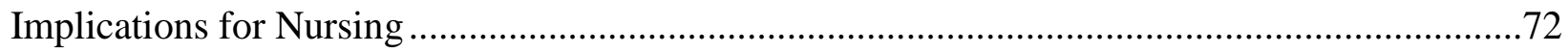

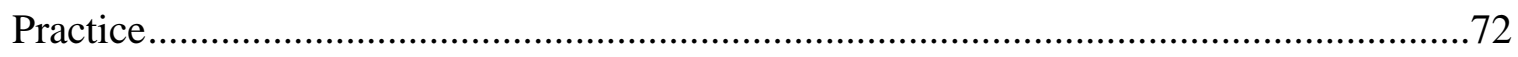

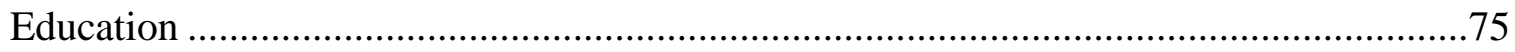

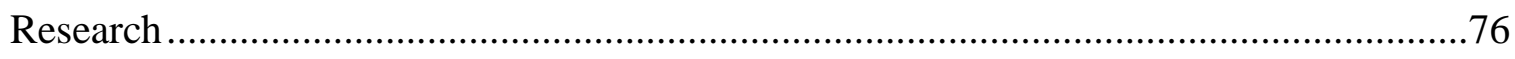

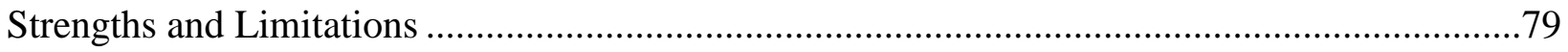

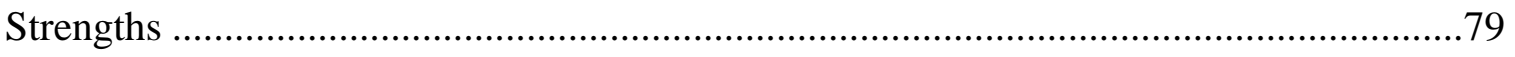

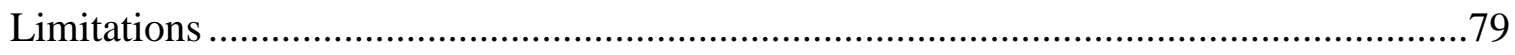

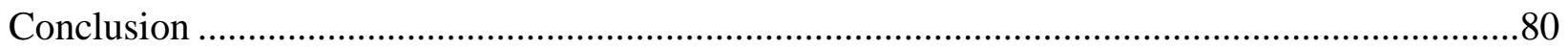

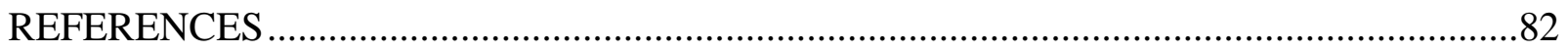

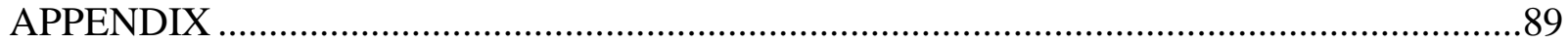




\section{Chapter One}

Introduction

Fatigue is a common and distressing symptom of pediatric cancer and cancer treatment. Yet, childhood cancer-related fatigue is a relatively new area of research and is often a neglected symptom in clinical practice (Yilmaz, Tas, Muslu, Basbakkal, \& Kantar, 2010). Much of the childhood cancer-related fatigue research has focused on recognizing, defining, and understanding contributing and alleviating factors. However, understanding what it is like for a young child (1-12 years of age) to live with fatigue "every day" and how the symptom shapes his or her day-to-day quality of life has not been studied concurrently. Although patient report of quality of life is preferred, parents are a good proxy when a child with cancer wishes not to speak, the child is physically unable, or he or she lacks the linguistic ability or cognitive skills to speak on their own behalf (Eiser \&Morse, 2001). Therefore, the purpose of this study was to describe the parents' observations and interpretations of childhood cancer-related fatigue and how it shapes their child's (1-12 years of age) day-to-day quality of life. The knowledge gained from this study enhances understanding of the psychosocial needs of the child experiencing fatigue from cancer, and supports assessment, diagnosis, recommendation and evaluation of evidence-based interventions known to alleviate fatigue among children with cancer and their families. Chapter one provides an overview of the study, its importance, and its relevance to clinical nursing practice. The chapter is organized accordingly: background, significance, and purpose.

\section{Background}

Childhood cancer-related fatigue is a complex symptom that is often poorly managed and is a relatively new area of research. Fatigue has been widely studied in the adult oncology 
population while "fatigue has seldom been studied in children" (Whitsett, Gudmundsdottir, Davies, McCarthy, \& Friedman, 2008, p. 95). "Health professionals...tend to pay more attention to other cancer related symptoms, such as nausea, vomiting, pain, and hair loss, than they do fatigue" (Yilmaz et al., 2010, p. 333). Gibson and colleagues report only $42 \%$ of healthcare providers always or almost always discuss fatigue as a possible side effect of cancer or cancer treatment (Gibson, Garnett, Richardson, Edwards, \& Sepion, 2005, p. 32). Gibson et al. report that health care professionals use a "range of assessment methods" to assess fatigue (Gibson, Edwards, Sepion, and Richardson, 2005, p. 313), but rarely use formal assessment tools (Gibson et al.; Yilmaz et al.). In a study that described how health care professionals define and assess cancer-related fatigue, all respondents reported assessing fatigue by listening to the patients' statements regarding "feeling tired" (Yilmaz et al.). Unfortunately, waiting for patients to discuss concerns of fatigue is not an adequate assessment technique; nor is it an indicator of the presence or severity of fatigue. According to Wu and colleagues (2009), children (ages 7-18 years) with cancer often acknowledge that they experienced cancer-related fatigue but did not share concerns with family members or healthcare professionals because they assumed nothing could be done to improve the symptom. Moreover, parents report not discussing concerns about their child's fatigue with a healthcare professional because they did not want to burden the professional with what is thought to be an inevitable symptom (Gibson, Garnett, et al.; Hinds \& HockenberryEaton, 2000). Yet, cancer-related fatigue can disrupt normal childhood development and family functioning, as well as, signal serious complications of cancer and its treatment. Thus, it is incumbent upon the health care professional to be more proactive in the assessment and management of the distressing symptom of fatigue. 
The symptom of fatigue has been described as having physical, mental, and emotional components (Chiang, Yeh, Wang, \& Yang, 2009; Davies, Whitsett, Bruce, McCarthy, 2002; Gibson, Garnett, et al., 2005; Hinds et al., 1999; Hockenberry-Eaton et al., 1998; Whitsett, et al., 2008; Woodgate, Degner,\& Yanofsky, 2003; Wu et al., 2009) that disrupt the child's and family's normal activities (Chiang et al.; Gibson, Garnett et al.; Woodgate et al.; Wu et al.), and impacts psychosocial function (Enskar \& von Essen, 2008). Yet, little is known about how childhood-cancer related fatigue shapes “every day" life or day-to day quality of life.

Although a universal definition of quality of life does not exist, most agree it is a “multifaceted construct of physical, emotional, psychological, and social components" (Hicks, Bartholomew, Ward-Smith, \& Hutto, 2003, p. 193). This understanding of quality of life is remarkably similar to how fatigue has been described, as having physical, mental, and emotional components (Chiang et al., 2009; Davies et al., 2002; Gibson, Garnett, et al., 2005; Hinds et al., 1999; Hockenberry-Eaton et al., 1998; Whitsett, et al., 2008; Woodgate et al., 2003; Wu et al., 2009). Yet, very few studies have concurrently examined childhood cancer-related fatigue and quality of life. The aim of this study was to move beyond recounting the physical, mental, and emotional aspects of the fatigue symptom by describing how these components of fatigue may shape the overall day-to-day quality of life for the young child with cancer.

The investigator of this study captured quality of life by constructing interview questions that were informed by the research of quality of life in pediatric oncology patients. Hinds and colleagues (2004) developed a definition and identified six domains of quality of life of pediatric oncology patients from two related qualitative studies that asked children and adolescents (8-18 years of age) about their quality of life while receiving cancer treatment. Data were analyzed using semantic-content method and the following definition of quality of life was developed: "an 
overall sense of well-being based on being able to participate in usual activities, to interact with others, and feel cared about, to cope with uncomfortable physical, emotional, and cognitive reactions, and to find meaning in the illness experience (Hinds, Gattuso, Fletcher, Baker, Coleman, Jackson et al. 2004, p. 767).” Additionally, six domains of quality of life were identified: "usual activities, social/family interaction, health status, symptoms, mood, and the meaning of being ill" (p. 767). "Finding meaning of being ill" (p.767) is a unique finding of this work.

Self-report is the preferred assessment method for quality of life (Hinds, 2010; Eiser, 2001). However, chronological age and developmental level pose a challenge in gathering selfreports of symptoms from the younger pediatric patient. In these situations, parent proxy report is appropriate (Eiser \& Morse, 2001) despite the noted discrepancies between child and parent report in the literature. "In general, parents perceive an illness to have more negative consequences than children themselves" (Eiser \& Morse, 2001, p. 348). A rationale for this discrepancy may be that "parents base their ratings on a series of events, whereas children and adolescents are more likely to base their scores on a single recent event" (Hinds, 2010, p. 22). In essence, the child is more likely to respond according to how they feel in the moment rather than over time. Since parents base their observations on a series of events over time, they are able to capture the "whole" picture and provide a longitudinal and more clinically relevant report than children. This rationale is significant in understanding the importance of parent proxy. Recent studies indicate that parents' reports of their child's quality of life is "strongly associated with clinical indicators than were the child's self-reported quality of life scores" (Hinds, 2010, p. 22). Hinds (2010) concluded this association may be due to the parents' observations of their child's behavior were informed by their "access to medical reports of their 
child's health status" (p. 32). This finding reinforces the importance of soliciting information from parents when assessing quality of life in the pediatric patient (Hinds, 2010).

Developmental stage is also linked to a child's experience of fatigue and its observable manifestations (Chiang et al., 2008; Hockenberry-Eaton et al. 1998; Wu et al., 2009). The industrious psychosocial and concrete intellectual development of school-age children, 6-12 years of age, influences how they identify and communicate fatigue characteristics, causes, and alleviating factors. The psychosocial developmental goal of the school-age child is to accomplish a sense of industry by achieving "a sense of personal and interpersonal competence through the acquisition of technologic and social skills. "School-age children are eager to build skills and participate in meaningful and socially useful work" (Hockenberry \& Wilson, 2011, p. 646). The school-age child is in the concrete-operational stage of cognitive development. The child is progressing "from making judgments based on what they see (perceptual thinking) to making judgments based on what they reason (conceptual thinking)" (Hockenberry \& Wilson, p. 648). Because of the school-age child's concrete thinking, physical limitations that impact industrious activities are recognized as problems of fatigue more frequently than mental or emotional dimensions of fatigue (Hockenberry-Eaton, et al, 1998). As the child's development advances, so does the ability to identify more emotional or mental aspects of fatigue. Younger school-age children, ages 7-9 years, describe more physical symptoms that impact play (Chiang et al.; Hockenberry-Eaton et al.). Older school-age children have more emotional symptoms, concerns about the burden they place on their family, (Chiang et al.; Gibson, Mulhall et al., 2005), succeeding in school (Chiang et al.), and worries about their ability to participate in activities with their peers (Hockenberry-Eaton et al.). School-age children identify fewer contributing and alleviating factors of fatigue than adolescent patients, parents, or health care providers (Hinds, 
Hockenberry-Eaton, Gilger et al., 1999). Factors contributing to cancer-related fatigue in schoolage children include the hospital environment, cancer treatment, and attempts to maintain prediagnoses activity level (Hinds et al.; Hockenberry-Eaton et al.). Alleviating factors include napping or resting more and interacting with family and friends (Hinds et al.; Hockenberry-Eaton et al.).

The toddler and preschool age groups are not included in the majority of childhood cancer-related fatigue studies. Only a few studies have included children two years of age and older (Gibson, Garnett et al., 2005; Meeske et al., 2004; Woodgate et al. 2003); to the author's knowledge, no studies have included children younger than two years. However, as with all developmental levels, fatigue has the potential to have a negative influence on the healthy development of these younger age groups. Active play is an important aspect of toddlers and preschool children. The psychosocial development goal of the preschool age child, 3-5 years of age, is to acquire a sense of initiative. Preschool children are "in a stage of energetic learning. They play, work, and live to the fullest and feel a real sense of accomplishment and satisfaction in their activities" (Hockenberry \& Wilson, 2011, p. 645). The child may experience feelings of guilt, anxiety, and fear when his or her behaviors differ from what is expected. The toddler years, 12-36 months of age, is "a time of intense exploration of the environment" (Hockenberry \& Wilson, p. 609). The psychosocial developmental task of toddlers is to achieve autonomy. "Successful mastery of the task of autonomy necessitates opportunities for self-mastery .... Opportunities for self-mastery are present in appropriate play activities, toilet training, the crisis of sibling rivalry, and successful interactions with significant others (Hockenberry \& Wilson, p. 610). An enhanced understanding of how fatigue shapes the "every day" life of toddlers, 
preschool and school-age children may benefit clinicians and improve the quality of care for children experiencing cancer-related fatigue and their parents.

The majority of research done on childhood cancer-related fatigue is focused on children 7 years of age or older. Only a handful of studies included preschool-aged children and toddlers; none studied infants (Gibson, Garnett et al., 2005; Meeske et al., 2004; Woodgate et al. 2003). This study builds upon previous research by eliciting parents' descriptions and interpretations of how fatigue from cancer shapes their toddler, preschool or school-age child's day-to-day quality of life.

\section{Significance}

Cancer is the leading cause of death by disease in children 1-14 years of age (Cancer Facts \& Figures 2010, 2010, p. 11). Pain, nausea, and fatigue are the most frequently reported adverse side effects of pediatric cancer and cancer treatment (Hedstrom, Haglund, Skolin, \& von Essen, 2003; Enskar \& von Essen, 2008). Pain and nausea are priorities in pediatric oncology care, and are routinely assessed and evaluated by healthcare providers. However, childhood cancer-related fatigue is often viewed as an inevitable symptom of cancer and cancer treatment leading to under-assessment by health care providers and self-management by families in the home and hospital environment (Gibson, Garnett, et al., 2005; Wu et al., 2009). Children and their families' often self-manage and fail to report fatigue because they feel the symptom is inevitable (Gibson, Garnett, Richardson, Edwards, \& Sepion, 2005; Hinds \& HockenberryEaton, 2001) and fear "bothering" the healthcare provider with a non-life threatening symptom (Hinds \& Hockenberry-Eaton, 2000).

Childhood cancer-related fatigue is not sleepiness or tiredness; fatigue is a distressing symptom that requires attention and support from pediatric oncology health care providers. The 
literature depicts fatigue as being frightening, distressing, and life-altering to children. According to Woodgate et al. (2003), children, adolescents, and parents commonly use the expression "wiped out" (p. 810) when describing fatigue. When a child is "wiped out" he or she experience a "state of limbo" (Woodgate et al., p. 810). While in this state, they feel as though they are not in the living world but not yet dead. As a result, the child and family put their lives on hold until the child regains adequate energy levels. Enskar and von Essen (2008) found the presence of fatigue as the primary symptom in poorer life satisfaction scores in children with cancer and the main reason for decreased interactions with others.

This study moves beyond previous qualitative and quantitative work of childhood cancerrelated fatigue by concurrently examining fatigue and quality of life. To the author's knowledge, no other primary research studies exist in which the main purpose was to concurrently examine fatigue and quality of life. The challenge is to understand how the physical, mental, and emotional aspects of the fatigue symptom may shape the child's every day quality of life. Furthermore, the significance of this study was that very few studies of fatigue have included children under the age of six, and this is the first study to include children under the age of two. While fatigue is a common and burdensome symptom of childhood cancer and cancer treatment, very little is known about "every day" quality of life of children living with fatigue and how health professionals can best help them to effectively manage this symptom. Therefore, the purpose of this study was to describe how the symptom shapes their child's day-to-day quality of life. This research supports the recommendations of The American Cancer Society's National Action Plan for Childhood Cancer by trying to better understand the effects of cancer on family functioning and identifying psychosocial support needs. This study contributes to nursing science and addresses knowledge gaps in the childhood cancer-related fatigue literature 
by describing the parent's perspective of the younger child's fatigue experience and how fatigue shapes the child's day-to-day quality of life.

\section{Purpose}

This study was prompted by personal clinical experience and the limited research in the area. The author has 13 years of pediatric oncology experience. During clinical practice the author recognized fatigue as a detrimental side effect of cancer and cancer treatment and questioned how fatigue impacted the child's and families' day-to-day life. The negative impact of fatigue on play and the ability to interact with others was a great concern. The author recalls caring for a preschool age child with cancer who barely had the energy to move from her bed to a nearby chair. Photo displays in the room depicted a "before" glimpse of the girl with cancer. The pictures revealed a blonde little girl riding horses and climbing on playground equipment with other children. The mother spoke about these happy times by always starting the recount with "before this..."

This study describes and improves understanding of parents' perspectives of what it is like for their children to live with fatigue "every day" and their observations of how it shapes their child's (1-12 years of age) day-to-day quality of life. A knowledge gap is evident in the childhood cancer-related fatigue research. Fatigue has been defined. Factors that may contribute or help to alleviate have been recognized; however, the manner in which the symptom shapes the child's day-to-day life has not been addressed. How fatigue shapes the child's relationships with family and peers, and how fatigue impacts age-appropriate activities, play, and school involvement has not been a focus of research. Furthermore, few studies of childhood cancerrelated fatigue have included children under the age of 6 years or parents of children younger than 6 years. This is the first study to include the younger toddler. The knowledge gained from 
this research helps health care professionals to assess fatigue, provide anticipatory guidance, and recommend evidence-based interventions known to alleviate fatigue, thus potentially improving the quality of life of pediatric oncology patients.

The method of this study was qualitative description, using conventional content analysis. Qualitative description is used to describe or explore events based on an individual's perspective; the findings are then reported in everyday language (Sandelowski, 2000; 2010). Both qualitative description and conventional content analysis were appropriate for the purpose and research question of this study.

\section{Research Question}

The question guiding this study was: How do parents describe their observations and interpretations of the way cancer-related fatigue shapes their child's day-to-day quality of life?

\section{Conclusion}

Childhood cancer-related fatigue is one of the most common and distressing symptoms experienced by children with cancer. Yet, the symptom continues to be under-recognized and under-managed in clinical practice. The aim of this research was to gain the parents' perspective of how cancer-related fatigue shapes their child's (1-12 years of age) day-to-day quality of life. The findings of this study hold valuable implications for both pediatric oncology research and clinical practice. The knowledge gained from this study improves understanding of the psychosocial needs of the child experiencing fatigue from cancer, and supports assessment, diagnosis, recommendation of evidence-based interventions known to alleviate fatigue, and evaluation of all children and families with cancer. 


\section{Chapter Two}

Review of Literature

Chapter two presents a detailed description of a literature search and synthesis of the literature related to childhood cancer-related fatigue. The review of literature is organized using the following main headings: method, literature findings, and synthesis. The literature findings section is organized accordingly: conceptual, methodological, and empirical. The conceptual section provides the history and the conceptual definition of childhood cancer-related fatigue. The methodological section is organized using two headings: quantitative methods and qualitative methods. The quantitative section describes the fatigue scales and quantitative methods used to study fatigue in children with cancer, and the qualitative section discusses the methods and analytical techniques used in the studies. The empirical section details the findings from research related to fatigue in children with cancer. Finally, the literature is synthesized to identify what is and what is not known about this symptom.

\section{Method}

The literature search and review of childhood cancer-related fatigue was conducted between February 2008 and February 2013. To obtain and review research of childhood cancerrelated fatigue across a variety of health-related disciplines, Comprehensive Index to Nursing and Allied Health Literature (CINAHL), Medline, PsycINFO, and Health Source were searched. The literature search was conducted by pairing the primary keyword 'fatigue' with each of the following: pediatric, childhood cancer, cancer-related and children, cancer-related and pediatric, children and cancer, pediatric and cancer, and pediatric, treatment and childhood cancer. Inclusion criteria were quantitative or qualitative studies and systematic reviews written in the English language, and research related to fatigue in children, ages 1-12 years, with cancer and 
receiving cancer treatment. Exclusion criteria were research studies focused exclusively on the adolescent population, fatigue in the childhood cancer survivor, and pediatric patients suffering from advanced disease. Reference lists were reviewed and citations that supported this research interest were obtained. A total of 25 studies met inclusion criteria and were organized and reviewed using The Matrix Method (Garrard, 2007).

\section{Literature Findings}

\section{Conceptual}

The literature pertaining to cancer-related fatigue in the adult population spans 25 years and contains a large body of knowledge. Although pediatric oncology providers recognized changes in activity levels in children with cancer or receiving treatment for cancer, no literature examining fatigue in children with cancer exists prior to 1998. Hockenberry-Eaton et al. (1998) were among the first to describe the characteristics, causes, and experiences of fatigue in children and adolescents with cancer in the research literature. The aim of these landmark studies was to understand the experience of childhood cancer-related fatigue from the perspective of the children and adolescents, their parents, and healthcare providers. In a foundational program of research, Hockenberry-Eaton, Hinds, and colleagues conducted focus groups with children ages 7-12 years, adolescent ages 13-18 years, their parents, and healthcare providers (HockenberryEaton \& Hinds, 2000). Data were analyzed using content analysis and findings were used to develop a conceptual model (Hockenberry-Eaton et al., 1999), and age-appropriate instruments to measure fatigue in children (Hockenberry et al., 2003). Four definitions of childhood cancerrelated fatigue were developed from this program of research: 1) school-age child's experience with fatigue 2) adolescent's experience with fatigue 3) families' perspectives of childhood cancer-related fatigue, and 4) healthcare providers' perspective of childhood cancer-related 
fatigue. Similarities and dissimilarities are found among the above four definitions of fatigue. All four portray cancer-related fatigue as being acute, episodic, or chronic; causing mental and physical symptoms; impacting normal functioning; having environmental and treatment-related influences; and recognizing rest as an alleviating factor (Hinds, Hockenberry-Eaton, Quargneti et al., 1999; Hockenberry-Eaton et al., 1999; Hockenberry-Eaton et al., 1998). The differences among the child's definition and the adolescent, family member, and healthcare provider definitions are: (a) the adolescent identifies more mental and emotional symptoms and recognizes medical and pharmacologic interventions (Hinds, Hockenberry-Eaton, Gilger et al., 1999) as alleviating factors of fatigue; (b) parents identify alleviating factors that are mediated by the family, including adjusting family schedule, encouraging the child to complete normal activities, and providing the child with physical and emotional support; and (c) healthcare provider definition of fatigue in the child with cancer includes the child's complete loss of will, uncooperativeness, and spiritual distress (Hinds, Hockenberry-Eaton, Quargneti et al., 1999). This program of research was the first to study childhood cancer-related fatigue and most commonly cited work pertaining to this issue.

\section{Methodological}

Quantitative methods. Hinds, Hockenberry-Eaton, and colleagues developed the most widely used scales to measure fatigue in children with cancer from the aforementioned work. The four instruments are the Child Fatigue Scale (CFS), Parent Fatigue Scale (PFS), and Healthcare Providers Fatigue Scale (SFS) (Hockenberry et al., 2003), and Fatigue ScaleAdolescent (FS-A) (Hinds, Hockenberry, Tong et al., 2007). The CFS, PFS, SFS, and FS-A can be completed in ten minutes or less and have documented reliability and validity (Hinds, Hockenberry, Tong et al.; Hockenberry et al., 2003) the fatigue scales have been utilized in 
descriptive ( Hinds, Hockenberry, Rai, Zhang, Razzouk, McCarthy et al., 2007; Perdikaris et al., 2008; Perdikaris et al., 2009), correlational (Hockenberry, Hooke, Gregurich, \& McCarthy, 2009) and quasi-experimental research (Ekti Genc \& Conk, 2008; Hinds, Hockenberry, Rai, Zhang, Razzouk, Cremer et al., 2007). Two studies have used all four scales, CFS, FS-A, PFS, SFS (Hinds, Hockenberry, Rai, Zhang, Razzouk, McCarthy et al.; Hinds, Hockenberry, Rai, Zhang, Razzouk, Cremer et al.).

Two additional fatigue scales are found in the literature, but have fewer documented uses, the PedsQL Multidimensional Fatigue Scale (MFS) and Pediatric Functional Assessment of Chronic Illness Therapy-Fatigue (pedsFACIT-F). The MFS (Varni, Burwinkle, Katz, Meeske, \& Dickinson, 2002) is an 18-item subscale of the Pediatric Quality of Life Inventory (PedsQL). The MFS was developed using constructs from the adult and pediatric literature and intended to measure both the child and parent perceptions of fatigue and has documented validity and reliability (Varni et al.). In a descriptive study using the PedsQL and MFS, Meeske, Katz, Palmer, Burwinkle, and Varni (2004) found children with brain tumors experience more fatigue and health-related quality of life problems than children diagnosed with acute lymphoblastic leukemia. Yeh et al. (2008) used the PedsQL and PFS in a prospective longitudinal study and found an association among higher levels of fatigue, corticosteroid use, and lower hemoglobin levels.

The pedsFACIT-F is an 11-item instrument intended to measure moderate to severe cancer-related fatigue in children and adolescents (Lai et al., 2007). The pedsFACIT-F instrument was developed from a pediatric fatigue item bank (pedsFIB), and has reported validity and reliability properties (Lai et al.). The current literature search did not yield any studies using the pedsFACIT-F. 
In addition to the fatigue scales, a variety of measurements are used to study childhood cancer-related fatigue. Wrist actigraphy, 15-item sleep diary, room entry, and exit checklists are used in descriptive (Hinds, Hockenberry, Rai, Zhang, Razzouk, McCarthy et al., 2007) and interventional (Hinds, Hockenberry, Rai, Zhang, Razzouk, Cremer et al., 2007) studies. Patients, parents, and healthcare providers often associate lower hemoglobin and hematocrit $(\mathrm{H} \& \mathrm{H})$ levels with higher reports of fatigue; however, conflicting results between $\mathrm{H} \& \mathrm{H}$ levels and fatigue scores are found in the literature (Hinds, Hockenberry, Rai, Zhang, Razzouk, McCarthy et al.; Perdikaris et al., 2008; Whitsett et al., 2008; Yeh et al., 2008). Most studies have not found a statistical significance between fatigue scores and H\&H (Hinds, Hockenberry, Rai et al.; Perdikaris et al.). Particular points in chemotherapy treatment (Meeske et al., 2004; Perdikaris et al.; Yeh et al.; Perdikaris et al., 2009; Hockenberry, Hooke, Gregurich, \& McCarthy, 2009) and corticosteroid use (Yeh et al.) are associated with higher reports of fatigue.

Qualitative methods. In addition to Hockenberry and Hind's program of research, three other qualitative studies focusing on cancer-related fatigue of the school-age child were found in the literature. Wu et al. (2010) conducted a phenomenological study aimed at exploring the life experience of fatigue from the perspective of Chinese children with leukemia. Data were collected from children and adolescent with leukemia, ages 7-12 years and 13-18 years using focus groups; data were analyzed using content analysis. The cultural influence on the child's physical, psychological, social, spiritual, and personal experiences of cancer-related fatigue were described using three themes. The three themes were identified as: "fatigue is an open interpretation among children and adolescents, fatigue is not a single-dimensional aspect, and struggles with fatigue and balancing of life suffering" (p. 53). The main findings of this study were: (1) children and adolescents found it difficult to describe fatigue, (2) physical, emotional, 
and situational factors of fatigue were identified, and (3) fatigue negatively affected participants' lifestyle.

In a grounded theory study Davies, Whitsett, Bruce, and McCarthy (2002) described children's cancer-related fatigue experiences from the perspectives of 13 children with leukemia or lymphoma, ages 5 to 15 years, and their parents. Data were analyzed by constant comparison and three typologies of childhood cancer-related fatigue were defined: (1) typical tiredness, normal or pre-diagnosis fatigue; (2) treatment fatigue, never experienced fatigue, unhealthy; and (3) shut-down fatigue, sustained loss of energy, and profound impact on life.

Chiang et al. (2008) conducted interviews, observations, medical chart reviews, and researcher's reflexive journals of 17 children, ages 7-18 years to describe the experience of cancer-related fatigue in Taiwanese children and adolescents. Using qualitative data analysis method, the study found the child's age has a significant impact on the experience of fatigue. Similar to the findings of Hockenberry-Eaton, Hinds, and colleagues, the younger school-child describes more physical symptoms of fatigue that impact play, while the older school-age child and adolescents describe fatigue as a symptom that affects not only physical dimensions but psychosocial aspects of living.

While research of cancer-related fatigue among children is a relatively new area of research and remains an under-studied topic (Whitsett et al., 2008) qualitative and quantitative studies have shed light on the characteristics and contributing and alleviating factors of fatigue. Four qualitative studies have described the child's experience with fatigue from cancer and cancer treatment; however, only one study conducted in the United States has obtained the school-age child's perspective of living with fatigue. The findings from this study were used to develop definitions and scales to measure fatigue. Several limitations in the knowledge of 
childhood cancer-related fatigue were noted:(1) few studies obtain the child's perspective of living with childhood cancer-related fatigue, (2) only one study from the child's perspective of living with cancer-related fatigue was used in instrument development, (3) younger children are not well represented in the literature, and (4) although the symptom has been describe little is known about how fatigue effects the child's "everyday" life.

\section{Empirical}

The following section provides the empirical findings of childhood cancer-related fatigue (see Appendix for detailed descriptions of each study). Twenty papers were retrieved and reviewed for empirical data related to children with fatigue from cancer. Data were reviewed, coded, and assigned a category using a color-coding system. Empirical findings of childhood cancer-related fatigue are presented using the following five categories: (1) physical, mental, and emotional symptoms; (2) terminology; (3) causes and alleviating factors; (4) assessment; and (5) effect on lifestyle and family system.

Physical, mental, and emotional symptoms. Children and adolescents with cancer identify physical and mental characteristics of childhood cancer-related fatigue (Chiang et al., 2009; Davies et al., 2002; Gibson, Mulhall et al., 2005; Hinds, Hockenberry-Eaton, Gilger et al., 1999; Hockenberry-Eaton et al., 1998; Wu,et al., 2009). School-age children describe more physical symptoms such as decreased physical activity and inability to play (Chiang et al.; Hinds, Hockenberry-Eaton, Gilger et al.). Older school-age children and adolescents discuss more emotional symptoms, such as worrying about school attendance (Chiang et al.; Wu, et al.), being a burden to their family (Chiang et al.; Gibson, Mulhall et al.; Ream et al., 2006) and missing social and sporting events (Hockenberry-Eaton et al., 1998). The developmental level has a great influence on the patient's perception of fatigue and ability to identify and communicate fatigue 
characteristics (Chiang et al.; Hockenberry-Eaton et al.). Parents (Davies et al.; Hinds, Hockenberry-Eaton, Gilger et al.) and healthcare providers (Hinds, Hockenberry-Eaton, Quargnenti et al.) identify similar characteristics of childhood cancer-related fatigue, including physical, mental, and emotional symptoms.

Terminology. The term fatigue is rarely used by patients, families (Chiang et al., 2009; Davies et al., 2002; Gibson, Mulhall et al., 2005; Hockenberry-Eaton et al., 1998; Woodgate et al., 2003; Wu et al., 2009;), and healthcare providers (Hinds, Hockenberry-Eaton, Quargnenti et al., 1999). Children and adolescents describe the phenomena as being tired (Chiang et al.; Hockenberry-Eaton et al.; Wu et al.), feeling wiped out (Gibson, Mulhall et al.; Woodgate et al.), and having no energy (Davies et al.; Wu et al.). Parents (Davies et al.; Hinds, HockenberryEaton, Gilger et al., 1999) and healthcare providers (Hinds, Hockenberry-Eaton, Quargnenti et al.) often reference energy levels when discussing fatigue.

Causes and alleviating factors. Children and adolescents with cancer, their parents, and healthcare providers identify the hospital environment, sleep changes, fear and worry, cancer treatment, and medication side effects as causes of fatigue (Chiang et al., 2009; Davies et al., 2002; Gibson, Garnett et al., 2005; Gibson, Mulhall et al., 2005; Hockenberry-Eaton et al., 1998; Perdikaris et al., 2008; Wu et al., 2009;). Most studies report no significant correlation between gender and fatigue (Genc \& Conk, 2008; Hinds, Hockenberry, Rai, Zhang, Razzouk, McCarthy et al.; Hinds, Hockenberry, Rai, Zhang, Razzouk, Cremer et al.). However, Perdikaris et al. (2009) report gender difference as the only demographic factor to impact overall fatigue scores; females reporting more fatigue symptoms than males ( $p=0.03$ ); ( p. 404). Co-existing symptoms, such as pain (Wu et al., 2009), nausea (Whitsett et al., 2008; Wu et al.), and sleep disturbances 
(Hinds, Hockenberry-Eaton, Gilger, 1999) are also identified as factors contributing to the fatigue experience.

The empirical literature reports a correlation between cancer treatment and fatigue. According to Perdikaris et al. (2008), fatigue scores of pediatric patients with cancer, excluding children with brain tumors, significantly increase during cancer treatment ( $\mathrm{p}=0.003) ;(\mathrm{p}$. 415). Similarly, Meeske et al. (2004) report most pediatric patients' fatigue scores decrease the longer the patient is without cancer treatment $(\mathrm{p}=0.008) ;(\mathrm{p} .2121)$. However, this differs in children with brain tumors. Children with brain tumors experience more profound fatigue that is not effected by cancer treatment phase, and report fatigue as a significant problem years after cessation of cancer treatment (Meeske et al.).

Depression and fatigue share similar attributes; often making it difficult to distinguish the two diagnoses. Convergence validity was evaluated by assessing the relationship between the CFS and The Depression Self Rating Scale (DSRS). All CFS factors were correlated with the DSRS, the highest correlation were items referring to lack of energy and changes in mood (Hockenberry et al., 2003). Child Fatigue Scale items related to daily functioning had the lowest correlation with DSRS. Thus, the authors suggested assessment of changes in daily activity may be helpful in differentiating depression or fatigue. Whitsett et al. (2008) also found a high positive correlation between CFS scores and Center for Epidemiological Studies depression Scale (CES-D) scores ( $\mathrm{p}=<.01) ;(\mathrm{p} .90)$.

Gibson and colleagues used surveys to gain a better understanding of parents and healthcare professionals perceptions of childhood cancer-related fatigue (Gibson, Garnett et al., 2005) and healthcare professionals knowledge and attitude of fatigue in children with cancer (Gibson, Edwards, Sepion, \& Richardson, 2006). Healthcare professionals (75\%) and parents 
(47\%) felt fatigue was a consequence of a combination of cancer and treatment (Gibson, Garnett et al.). Forty-three percent of healthcare professionals report feeling that fatigue is "not really understood" (Gibson, Garnett et al., p. 32), and 44\% of parents thought fatigue was an inevitable part of cancer and cancer treatment that had to be tolerated (Gibson, Garnett et al., p. 32).

Although adolescents (Hinds, Hockenberry-Eaton, Gilger et al., 1999) and healthcare professionals (Gibson, Garnett et al., 2005; Hinds, Hockenberry-Eaton, Gilger et al., 1999) find that blood transfusions alleviate fatigue, the majority of studies find no statistically significant correlation between fatigue scores and hemoglobin levels (Genc \& Conk, 2008; Hinds, Hockenberry, Rai et al., 2007; Perdikaris et al., 2008). A statistically significant relationship was noted by Yeh et al. (2008). Interestingly the studies showing no relationship used the CFS, while Yeh and colleagues used the MFS. A possible explanation for the conflicting findings may be the scale used to measure fatigue.

In contrast to ambiguous findings associated with hemoglobin levels, environmental disruptions and medications are associated with higher fatigue scores. The chemotherapy agent, doxorubicin, was recognized as contributing to lower carnitine levels and negatively impacting CFS and FS-A scores more than comparison agents, cisplatin and ifosfamide (Hockenberry et al., 2009). Yeh el al. (2008) found corticosteroids, an essential part of chemotherapy treatment, were associated with a significant increase in fatigue scores. Another contributor associated with higher fatigue scores are nocturnal awakenings at home and in the hospital environment (GedalyDuff et al., 2006; Hinds, Hockenberry, Rai, Zhang, Razzouk, McCarthy et al., 2007; Perdikaris et al., 2009).

Children, parents, and healthcare professionals identify the environment, cancer treatment, and social influences as contributing to fatigue. Similar factors are recognized in 
helping to alleviate fatigue in children with cancer. Because of their concrete thinking, children identify fewer alleviating factors of fatigue than the adolescent patient (Chiang et al., 2009; Hockenberry-Eaton et al., 1998; Wu et al., 2009). Children recognize relaxation, visitors, and fun activities as alleviating factors of fatigue, whereas adolescents find blood transfusions, medications, going outside, and physical therapy helpful (Hinds, Hockenberry-Eaton, Gilger, et al., 1999). Parents view themselves as playing a major role in decreasing their child's fatigue by altering family schedules and providing protected rest time (Hinds, Hockenberry-Eaton, Gilger, et al.).

Hinds, Hockenberry, Rai, Zhang, Razzouk, Cremer, et al. (2007) and Ekti Genc and Conk (2008) have conducted studies that implemented interventions aimed at reducing childhood cancer-related fatigue. An enhanced physical activity (EPA) intervention, pedaling a stationary bicycle for 30 minutes twice a day, was deemed feasible, but was not statistical significant in decreasing fatigue scores (Hinds et al.). An educational nursing intervention designed to decrease cancer-related fatigue in children, ages 7-12 years, was evaluated in a randomized, controlled study (Ekti Genc \& Conk). Sixty children and their parents were enrolled in the study. Participants assigned to the control group received standard nursing interventions. Participants assigned to the intervention group received verbal and written educational materials regarding fatigue, including appropriate activities, promotion of nutrition, and energy preservation. The children in the intervention group also had uninterrupted night time sleep, were encouraged to have less daytime napping, and ambulated in the hallways. The intervention group had lower fatigue scores ( $\mathrm{p}<.00)$; (Ekti Genc \& Conk) on the CFS and PFS compared to the control group. Assessment. Although fatigue is one of the most common side effects experienced by children with cancer, assessment of the symptom and child and parent education continues to be 
overlooked in clinical practice. Sixty-five percent of pediatric healthcare providers report fatigue as a serious issue for children with cancer (Gibson, Garnett et al., 2005). Yet, Gibson et al. (2005) found less than half (42\%) of healthcare providers always or almost always discuss fatigue as a possible side effect of cancer and cancer treatment (p. 32). Fewer than half of healthcare provider respondents (48\%) assess fatigue and only one of 30 use a fatigue assessment instrument to identify patients with fatigue (Gibson et al., 2006, p.313). Yilmaz et al. (2010) report all 56 participants assess fatigue by the patient stating that they are tired, no participants report using a scale to measure the symptom. The majority of healthcare providers report never receiving formal training related to childhood cancer-related fatigue (Gibson et al., 2006; Yilmaz et al.); however, $75 \%$ report they would benefit from further education about childhood cancerrelated fatigue (Yilmaz et al, p. 333).

Effect on lifestyle and family system. Gibson et al. (2005) found that forty-nine percent of parents indicate their child's fatigue has a major impact on family lifestyle. The family system was disrupted by altering the family schedule to accommodate the needs of the fatigued child (Hinds, Hockenberry-Eaton, Gilger et al., 1999) and requiring the entire family to put their lives on hold while waiting for the child to regain energy (Woodgate et al., 2003). Fatigued children were aware of the effects of fatigue on the family system (Chiang et al., 2009; Gibson, Mulhall et al., 2005), and report feeling frustrated and worried about the burden their illness put on their families. According to Wu et al. (2009), children report the family has a great influence on how the Chinese child experiences living with fatigue. "Parents arranged and decided everything for their children regardless of the children's opinion" (Wu et al., p. 54). Additionally, the traditional Chinese view of illness management influenced how the family managed fatigue, by overseeing child's food intake and restricting activities. 
The extent to which the school-age child's lifestyle is impacted by fatigue from cancer is not well understood. However, Wu et al. (2009) found Chinese children and adolescents with cancer recognize fatigue as having a "negative effect on their life in areas of family, school, and social interaction" (p. 56). According to Chiang et al. (2008), Taiwanese children with cancer have similar concerns. The Taiwanese culture holds a high value in school achievement; thus, older school-age children and adolescents fear failing school due to their inability to attend because of fatigue. Poor school attendance not only leads to fear of school failure, but produces concerns related to peer relations and causes missed opportunities for social interaction (Chiang et al.).

Although childhood cancer-related fatigue continues to be understudied and underrecognized in clinical practice, research findings have improved understanding of the troublesome symptom. The main findings of the empirical sections are: (1) the child's perception of fatigue is influenced by developmental level; (2) children and adolescents, their parents, and healthcare providers describe physical, mental, and emotional aspects of fatigue; (3) fatigue is an unpredictable symptom and may be experienced in varying degrees; (4) children indicate fatigue effects daily living and family functioning; (5) the term fatigue is rarely used to describe the phenomenon; (6) fatigue is viewed as an inevitable part of cancer and cancer treatment; (7) fatigue is correlated to depression symptoms; (8) assessment and management of fatigue are not common in oncology clinical practice; and (9) childhood cancer-related fatigue has a significant effect on the family system.

\section{Synthesis}

Fatigue is a troublesome symptom of pediatric cancer and cancer treatment. The symptom is recognized as having physical, mental, and emotional dimensions in which 
perception of the experience is greatly influenced by developmental stage. The environment, cancer treatment, and social influences are identified as contributing and alleviating factors of fatigue. Qualitative and quantitative methods are used in research related to fatigue in children with cancer and cancer treatment. Although childhood cancer-related fatigue research has increased dramatically over the past ten years, there are no studies aimed at describing the impact of childhood cancer-related fatigue on quality of day-to-day life, including peer relationships, school attendance, activity participation, and family functioning. The knowledge gained from this study improves our understanding of the psychosocial needs of the family and child experiencing fatigue from cancer. More imperative is that this research supports assessment, diagnosis, planning, intervention development, and evaluation of childhood cancer-related fatigue, and has the potential to improve the quality of life of children with cancer and families living with children with cancer.

\section{Conclusion}

Childhood cancer-related fatigue is one of the most common and distressing symptoms of pediatric cancer. Yet, the symptom continues to be overlooked in clinical practice as a problematic and manageable symptom of cancer and cancer treatment. As a result, both children and family function suffer because of lack of assessment of one of the most common side effects of pediatric cancer. The aim of this research was to gain the parents' perspective of how cancerrelated fatigue shapes the child's day-to-day life. The findings from this study hold valuable implications for pediatric oncology research and clinical practice. 


\section{Chapter Three}

Method

This chapter provides an overview of the methodology and analytical technique used for this study. This study was designed and conducted using the methodological underpinnings of qualitative description. The qualitative description method is appropriate when the purpose is to describe or explore events based on an individual's perspective, and then present the findings of the study in everyday language (Sandelowski, 2000; 2010). Sandelowski (2010) describes qualitative descriptive studies as producing "findings closer to the data as given, or data-near" (p. 78). The findings are not reported using highly abstract frameworks, but the researcher presents "the facts of the case in everyday language" (Sandelowski, 2000, p. 336). Content analysis is the recommended analytic technique for this method; conventional content analysis was used in this study. Both qualitative description and conventional content analysis were appropriate choices for the purpose and research question of this study: How do parents describe their observations and interpretations of the way cancer-related fatigue shapes their child's day-to-day quality of life?

This chapter will provide the philosophical underpinnings of qualitative description and conventional content analysis, followed by a detailed description of the methods used in this study. The following headings will be used to organize the chapter: philosophical underpinnings, content analysis, participants, data collection, data analysis, and protection of human subjects.

\section{Philosophical Underpinnings}

The most commonly used qualitative methods are phenomenology, ethnography, and grounded theory. These valuable methods are rich in history, rooted in theory, and derived from multiple disciplines. Often in an attempt to adhere to the traditional methods of qualitative 
research, investigators claim to be following a certain method but abandon the philosophical underpinnings of that particular method. Sandelowski (2000) explains that qualitative work have similar "hues, tones, and textures" (p. 337). These common threads among qualitative methods often mislead investigators. Studies are mistakenly classified as a particular method because of common "hues, tones, and textures"; however, the design, sample, and analysis does not represent the particular method at all. Qualitative description is often used in nursing research, but erroneously classified as "something else". The following section provides an overview and philosophical underpinnings of the often "un-named" qualitative method, qualitative description (Sandelowski, 2000).

The aim of qualitative description method is to present the facts of data and observations in everyday language that can be easily understood by others and readily applied to nursing practice (Sandelowski, $2000 \&$ Thorne, 1997). Qualitative description offers an alternative research method that is appropriate when asking general questions and seeking to understand the particulars of a problem (Thorne). The method is useful when asking straight-forward and general questions that want to know the "who, what, and where of events" (Sandelowski, p. 339). The findings are a "straight descriptive summary" (Sandelowski, p. 338) that assist in identifying patterns of a health and illness experience (Thorne).

Qualitative description is a generic or basic method, as it does not have roots in a particular discipline (Sandelowski, 2000). Qualitative description is infrequently identified as a distinct methodology (Sandelowski, 2010) however; Sandelowski argues that qualitative health research is often mislabeled. Researchers claim "to have used methods (e.g., grounded theory, phenomenology) to produce findings that show no evidence these methods were used"' (p. 77). Although qualitative description is not bound to sociological, philosophical or anthropological 
disciplines, the method is not devoid of philosophical underpinnings. Qualitative description is grounded by naturalism (Sandelowski, 2000). The goal in naturalistic inquiry is not to "disturb" the phenomena under study. Rather, the study should be designed and techniques used that captures the phenomena in its natural state and allows participants to react in the same manner as if they were not being studied or observed (Lincoln \& Guba, 1985; Sandelowski, 2000).

Qualitative description is not a "highly interpretive" research method, but produces "findings closer to the data as given, or data-near" (Sandelowski, 2010, p.78). The results are closer to the data as provided by the participant rather than "re-present events in other terms" (Sandelowski, 2000, p. 336), as would be done with more interpretive qualitative methods such as phenomenological, ethnographic, or grounded theory. "Not highly interpretive," does not negate the importance of analysis or render the method as easy or useless; Qualitative descriptive research still requires interpretation. "All inquiry entails description, and all description entails interpretation" (Sandelowski, 2000, p. 335).

Sandelowski (2010) describes qualitative description as less interpretive than some of the qualitative methods but more interpretive than quantitative description. Quantitative description involves the a priori selection of variables and uses statistical analyses to summarize research findings. Preconceived variables set boundaries around what the participants can share about the experience, thus limiting what investigators can learn about contextual issues surrounding the phenomena of study. In qualitative description studies, investigators ask open-ended or semistructured questions which offer participants the opportunity to share experiences about the phenomena that may not have been anticipated or included in a questionnaire or survey. Data may be collected by focus groups or individual interviews using open or semi-structured questions, observing behaviors, and studying documents, such as patient records. 


\section{Content Analysis}

Qualitative content analysis is the ideal analytic technique for qualitative description studies (Sandelowski, 2000). Qualitative content analysis may be used in either inductive or deductive approaches. The inductive approach is most fitting when little is known about the phenomenon, and deductive is most fitting when the "analysis is operationalized on the basis of

previous knowledge" (Elo \& Kyngas, 2007, p. 109). Inductive approaches move from specific to more general assumptions. By contrast, a deductive approach moves from a general theoretical base to more specific. The purpose of the study determines the type of analytical approach utilized in qualitative description (Elo \& Kyngas, 2007). This study used an inductive approach, conventional content analysis, because there is no literature related to how cancer-related fatigue shapes a child's day-to-day quality of life.

Conventional content analysis is "generally used with a study design whose aim is to describe a phenomenon" (Hsieh \& Shannon, 2005, p. 1279) and in areas in which relatively little is known. The goal of conventional content analysis is to identify key categories found in the data (Hsieh \& Shannon). Preconceived categories or theoretical paradigms are avoided in content analysis. In other words, investigators "allow the categories and names for categories to flow from the data" (Hsieh \& Shannon, p. 1279). The lack of preconceived categories result in findings that are based on "participants" unique perspectives and grounded in the actual data" (Hsieh \& Shannon, p. 1280). Conventional content analysis was a good fit for this study because little is known about the day-to-day quality of life in children experiencing cancer-related fatigue making the development of preconceived categories implausible. 


\section{Participants}

\section{Inclusion Criteria}

Inclusion criteria for this study were (1) a parent (or primary caregiver) of a child age 112 years with cancer and who was in the induction, consolidation, or maintenance phase of cancer treatment; and (2) and the ability to speak and understand the English language. There was a third criterion that required the parent must report that their child had experienced tiredness or fatigue since being diagnosed with cancer. Parents were not reporting fatigue symptoms, thus making them ineligible for the study. This criterion was deleted after consulting with the committee and making appropriate IRB changes.

\section{Exclusion Criteria}

Individuals were not included in the study if (1) they were not the primary care giver of a child with cancer, (2) the child with cancer did not meet the age requirement, (3) the child was no longer receiving cancer treatment, or (5) the parent did not speak and understand the English language.

\section{Sampling}

This study used purposeful sampling. Purposeful sampling techniques are preferred for qualitative description studies (Sandelowski, 2000; 2010). The purposeful sampling technique of maximum variation and snowball sampling was utilized. Maximum variation is defined as selecting participants from a wide range of different demographics (Sandelowski, 2000). The diversity among the participants allows the researcher to "explore common and uncommon unique manifestations of a target phenomenon across a broad range of demographically varied cases" (Sandelowski, 2000, p. 338), and to provide a "richer variation of the phenomena under study” (Graneheim \& Lundman, 2004, p 110). 
To gain maximum variation the researcher purposefully designed the inclusion criteria to include all pediatric cancer diagnoses and children in any phase of cancer treatment. Because the most common types of cancer in children are leukemia and malignant tumors of the central nervous system, it was expected that the majority of participants for this study be parents of children with leukemia or brain tumors. Surprisingly, the study did not include a parent of a child with a brain tumor. The majority of the participants were parents of children with leukemia $(n=8)$. The other participants were two parents of children with neuroblastoma (a cancer of the nervous system) and a parent of a child with nodular lymphocyte predominant Hodgkin disease. Most children were in the consolidation or maintenance phases of cancer treatment. The length of cancer treatment ranged from 3-36 months of cancer treatment with the average length of cancer treatment 14 months.

Snowball sampling is used when a population is limited and access to the population may be difficult to obtain. Because of the relatively small pediatric oncology population, snowballing sampling is appropriate. Participants' parents were asked to recommend others that met the inclusion criteria and would be interested in participating in the study. However, snowballing technique did not yield participant referrals for this study.

\section{Recruitment procedures}

The investigator has a positive working relationship with the West Virginia University (WVU) Children's Hospital oncology team. The investigator has work experience with a number of the oncology team members and has had the opportunity to work with newer members of the team while conducting a pilot study, spring of 2009. This study used the following IRB approved recruiting procedures: (1) The investigator provided an overview of the study and explained the inclusion and exclusion criteria to oncology team members, including two oncologists, an 
oncology nurse, a social worker, and two primary nurses of the Children's Hospital Infusion Center; (2) Flyers advertising the study were displayed in the infusion center and infusion center waiting room; (3) The oncology team was provided a copy of the informational letter (Appendix B); (4) Individuals meeting inclusion criteria were informed of the study by a member of the oncology team by verbally explaining the study, providing the an informational letter, or mailing the informational letter to potential participants; (5) Participants then contacted the investigator using the provided contact information. The telephone conversation included a brief introduction of the investigator and an overview of the purpose, risk, benefits, and confidentiality of the study. Inclusion and exclusion criteria were reviewed at this time. A face-to-face, video call, or telephone recruitment meeting time was scheduled with the prospective participant at the end of the conversation; (6) The recruitment meeting reinforced and provided more detail regarding the research, purpose of the project, participant's role, and risk and benefits of participation. The investigator explained three options for conducting the interviews and got verbal consent to conduct the interview: (1) face-to-face, in the participant's home, West Virginia University Children's Hospital Infusion Center, or West Virginia University Children's Hospital; (2) video call using Skype; or (3) telephone interview. Setting of interviews was decided by: participants' preference, distance from home, and availability of a computer. Place, time, and dates of interviews were established during the recruitment meeting.

The recruitment measures just described were attempted for four-months, yielding only one participant. At that time, inclusion and exclusion criteria were changed and recruitment efforts were revised. The following changes were submitted and approved by the IRB: (1) to no longer include "fatigue" as part of the inclusion criteria; and (2) to extend referral efforts from the Physician Office Center (POC) Infusion Center, to include 6 East (WVU Children's Hospital) 
and WVU Charlestown Division. The investigator became more vigilant in communicating with the oncology team members about the importance of maintaining advertisement displays and distributing informational letters to potential participants. Also, the investigator became more "present" in the infusion center by making weekly visits during high volume times. This encouraged the team to introduce the study and allowed potential participants to put a "face to a name.” Being present in the infusion center was significant and the most helpful change in the recruiting process. Ten more participants were enrolled in the study within the next year. By November 2012, the investigator conducted eleven interviews with a parent, parents, or a primary caregiver of a child (1-12 years of age) with cancer.

\section{Setting}

Data were collected using face-to-face and telephone interviews. All participants were informed of the option to complete the interview by video calling, but all participants declined this format. The data collection method was decided during the recruitment meeting and based on the participant's preference. Five face-to-face interviews were conducted in the infusion center, in a quiet, private room. Two interviews were conducted in a private hospital room. Four interviews were conducted by phone, using a land line phone in the privacy of a home office.

A pilot study that was conducted in 2009 helped to determine the most efficacious means to accomplish participant interviews. The pilot interviews were conducted in the infusion center using a private room. Yet, noise and disruption was a problem. Therefore, modifications were implemented for this study to avoid similar problems: securing a private room located in a low traffic area and placing a DO NOT DISTURB sign on the door. These modifications were also used when conducting interviews in the hospital setting. 


\section{Data Collection}

Data were gathered from eleven interviews with a parent, parents, or primary caregiver, of a child (1-12 years of age) with cancer. Six interviews were conducted with the mother of the child. Two dyadic interviews, comprising of the mother and father, were conducted. Two interviews were conducted with the father. One interview was with a non-custodial father and paternal grandfather. The interviews ranged from 17 minutes to 55 minutes in length, with a median of 27 minutes per interview. The interviews were semi-structured and guided by the following questions:

1. How would you describe what a "good day" was like for (child's name) before the cancer?

2. How has having cancer been like for (child's name). Tell me more.

3. Have you noticed any changes in the way (child's name) acts since he/she got cancer? Tell me more.

a. Have you noticed any changes in what (child's name) could do, like playing and other things before he/she got cancer? Tell me more.

4. What do you think is causing these changes?

5. Have you noticed that (child's name) seems more tired than before he/she got cancer? Tell me more.

6. Has the tiredness gotten in the way of him/her being able to enjoy time with family and/or friends? Tell me more.

The investigator used the same data recording method for face-to-face and telephone. Verbal communication was recorded using a small digital recorder. The data were de-identified, transcribed, and cleaned. The de-identifying process included removing participants' names, 
family members' names, references to particular healthcare providers, and health care systems. Data were transcribed by either the investigator or an experienced medical transcriptionist who was familiar with HIPPA regulations.

The investigator cleaned the data by removing all the questions and appraising each transcript for accuracy by simultaneously listening to the digital recording and reviewing transcripts. The tapes were then permanently erased using the DELETE function on the digital recorder.

The transcribed, clean data were managed using the text management system, Atlas.ti 6.2. Atlas.ti 6.2 is a software management system that helps the qualitative researcher to organize, store, and manage data. The Atlas.ti 6.2 system was installed on the investigators home computer that was protected by a password and kept in a locked, private office. Appropriate confidentiality measures were employed to protect the participants' privacy during the entire data collection process.

\section{Data Analysis}

The data were analyzed using conventional content analysis method. Data analysis began when data were being collected and transcribed. The investigator conducted the conventional content analysis using the process outlined by Hsieh and Shannon (2005, p. 1280) (a) data were

read and re-read multiple times, (b) data were read word-by-word, (c) codes were derived, (d) notes of impression were made, (e) labels for codes unfolded, (f) codes were sorted into categories, and (g) organized into hierarchical structure. The Atlas.ti 6.2 data management system was used to organize, store, and conduct initial coding and labeling. Microsoft Word was used to sort codes into categories and organize into hierarchical structure. Additionally, the investigator was guided by the expertise of a dissertation chairperson. 
The investigator began by reading each transcript multiple times. Reading the transcripts multiple times allows the researcher to become fully immersed in the data and have a solid understanding of "the whole" (Hsieh and Shannon, 2005, p. 1279). The investigator then read the transcripts word for word, highlighting and coding text that discussed fatigue and/or quality of life. Initially, the investigator directly used participant's words as codes. Hsiesh and Shannon describe the first step in developing codes as "highlighting the exact words from the text that appear to capture key thoughts or concepts" (p. 1279). The investigator then made notes of impressions and thoughts, by using the "memo" feature of Atlas.ti 6.2, and then developed labels for the initial codes. An initial analysis is performed by making notes of impressions and thoughts, and "as this process continues, labels for codes emerge that are reflective of more than one key thought" (p. 1279). As the labels for codes unfolded the transcripts were recoded to reflect the new codes. When all eleven transcripts had been coded, the investigator reviewed each code for clarity and cohesiveness. At this time, some codes were combined and others were divided into subcategories. The codes were then sorted into seven categories, and several subcategories. The codes were sorted into categories "based on how different codes were related and linked" (p. 1279). The categories were then organized into a "hierarchical structure" (Hsiesh and Shannon, p. 1280). The investigator of this study used the concept of fatigue and domains of quality of life as a framework to develop and organize the categories into a hierarchal structure. Rigor

Content analysis method is used to quantify words, but also to seek meaning and context (Downe-Wamboldt, 1992). A major threat to the trustworthiness of studies employing this method is the failure to "develop a complete understanding of the context", and identify key categories that accurately represent the data (Hsieh \& Shannon, 2005, p. 1280). Credibility, 
dependability, and transferability are the measures that need to be achieved in order to obtain trustworthiness (Graneheim \& Lundman, 2004).

Credibility refers to the focus of the research and "how well data and processes of analysis address the intended focus" (Graneheim \& Lundman, 2004, p.109). Proper preparation is fundamental to the credibility of a research study (Graneheim \& Lundman; Elo \& Kyngas, 2007). The first consideration in preparation is to use a suitable research method and select appropriate participants. The next step is to select the unit of analysis. Graneheim \& Lundman suggest "the most suitable unit of analysis is whole interviews or observational protocols that are large enough to be considered a whole and small enough to be possible to keep in mind as a context for the meaning unit, during the analysis process" (p. 106). Credibility also refers to "how well categories and themes cover data" (Graneheim \& Lundman, p.110). Credibility of category and theme development may be met by seeking agreement and showing representative quotes. The investigator of this study used the following measures to achieve credibility: (a) utilized the expertise of the dissertation chair and committee during the research process, including decisions related to study design and participant selection; (b) used portions of interviews that relate to childhood cancer-related fatigue and the six domains of quality of life; (c) sought agreement among dissertation chair and committee members (Downe-Wamboldt, 1992; Graneheim \& Lundman); (d) validated the results with participants; (e) reviewed the developing categories using conceptual and empirical findings (Elo \& Kyngas); and (f) used direct quotes to support the abstraction of categories (Elo \& Kyngas).

Dependability is the second component of trustworthiness. Dependability is "the degree to which data change over time and alterations made in the researcher's decisions during the analysis process" (Granheim \& Lundman, 2004, p. 110). As data collection proceeds new 
insights into the phenomenon may occur, causing the interviewer to narrow or focus in on a particular area. To avoid inconsistent data collection, all interviews should include questions that cover all areas (Graneheim \& Lundman, 2004). Additional clarifications "about similarities and differences of content" (Graneheim \& Lundman, 2004, p. 110) may be addressed by having open discussions among the dissertation committee members. The following steps were employed to ensure dependability: (a) used semi-structured questions to guide interviews, ensuring all areas were covered; and (b) maintained open communication with dissertation chair.

Transferability is the final aspect of trustworthiness of qualitative research. Transferability can be achieved by properly and thoroughly discussing research methods and reporting findings. The following measures were used when reporting findings from this study: (a) provided a detailed report to facilitate a clear understanding by readers (Elo \& Kyngas, 2007; Graneheim \& Lundman, 2004); (b) addressed relevant theories or other research findings in the discussion section of study (Hsieh \& Shannon, 2005); (c) provided suggestions for nursing practice, teaching, and research (Hsieh \& Shannon); and (d) demonstrated a link between results and the data by including representative quotes (Elo \& Kyngas; Graneheim \& Lundman).

\section{Protection of Human Subjects}

Approval of this study was obtained through the IRB at West Virginia University. The application for this study met the exempt review criteria. Ethical considerations of the participants were a priority during each phase of the study. Respect and autonomy was achieved by explaining and reinforcing participants' right to refuse to answer certain questions and the freedom to decline or discontinue participation in the study at any time.

Potential participants received an honest explanation of the study during the recruitment meeting. Voluntary participation was emphasized. Following the explanation of the study and the 
participants verbalizing a desire to participate, verbal consent of the parent or primary caregiver was obtained. The investigator reinforced that participation in the study could be ceased at any time, was completely voluntary, and did not affect healthcare services.

\section{Potential Risks}

There were no foreseeable risks or harm associated with participation in this study. While participants may not have gained a direct benefit from participating in this study, it offered the parent an opportunity to talk about what it is like to for their child to live with cancer. As a result, the parents may benefit from being able to voice their concerns and potentially help to improve cancer care.

\section{Confidentiality}

Strict confidentiality measures were implemented to protect all participants. Identifying information that was transcribed was removed, and following transcription the entire interview was erased using the DELETE function on the digital recorder. Computer files housing deidentified information were secured by a password protected database in a private locked home office.

\section{Conclusion}

The aim of this research was for parents to describe and interpret the way cancer-related fatigue shapes their child's day-to-day quality of life. This study was designed and conducted using the methodological underpinnings of qualitative description. Data were gathered from eleven interviews with a parent, parents, or primary caregiver, of a child (1-12 years of age) with cancer, and analyzed using conventional content analysis method. Credibility, dependability, and transferability measures were implemented to achieve trustworthiness of the study findings. 


\section{Chapter 4}

\section{Findings}

Within chapter four, are the findings of this qualitative study that describes parents' observations and interpretations of the way cancer-related fatigue shapes their child's day-to-day quality of life. Contents of this chapter include information about the participants, a report of findings, including direct quotes to support the abstraction of categories, and a discussion of how rigor was maintained throughout the research process. The chapter is organized using the following headings: participant demographics, study findings, and maintenance of rigor.

\section{Participant Demographics}

The researcher of this study conducted eleven interviews with a parent, parents, or a primary caregiver of a child (1-12 years of age) with cancer. Nine participants resided in West Virginia and two in Maryland; all participants' children were receiving cancer treatment at West Virginia University (WVU) in Morgantown. Parents spoke about the time constraints and financial hardships related to a lengthy commute to WVU. Most participants' travel time to the infusion center was between one and four hours.

The first interview was conducted on 11/21/2011; the eleventh interview was completed on 11/23/2012. The interviews ranged from 17 minutes to 55 minutes in length, with a median of 27 minutes. Five face-to-face interviews were conducted at the West Virginia University infusion center. The interviews were completed in a quiet, private room. The children were in the infusion center but not present during the interview. Two interviews were conducted in the hospital setting. These interviews were completed in the patient's private hospital room. One child was taken to the playroom by child life volunteers. A ten-year-old child decided he would like to stay in his room while I spoke to his parents. He played video games and watched 
television as I spoke to his parents in a distant corner. Four interviews were conducted by phone in the privacy of the researcher's home office. The option of video calling was offered but all participants declined this format.

Of the eleven interviews, six were conducted with the child's mother. Three of the women were married, all had at least one other child at home. One woman was divorced and the father remains actively engaged in the child's life. Two women were single and they were the sole provider of care. The biological fathers were not involved in their children's lives.

Two dyadic interviews were done with married couples. Both families were comprised of a mother, father, a child with cancer and another "well" child in the home. The mother was the primary source of information during both interviews, with the father adding information or clarification when the mother asked. During both interviews the mother sporadically asked the father for additional information or clarification, and occasionally the father would interject.

Two interviews were conducted with the father of a child with cancer. In one case, the father had four biological children and two adopted children; one of the children he adopted as a newborn developed cancer. His wife died one year following the adoption of the child. The other participant was a stay-at-home father. His wife works full-time and he cares for their two children and his ailing mother.

One interview included a non-custodial father and custodial paternal grandfather, who is the child's legal guardian and primary caregiver. The grandfather has custody of the child with cancer and sibling because of parent's incarceration due to drug related problems. At the time of the interview, the child's father was out of jail and an active participant in the child's daily life. The mother has weekend visitation rights, but she does not visit on a regular basis. 
During the interviews, participants were asked to provide some information about their child or grandchild who had cancer. All of the children with cancer were Caucasian and their ages ranged from 2-12 years of age with the mean age of 6 years. The length of cancer treatment ranged from 3-36 months, with a mean length of cancer treatment of 14 months. Ten of the children did not have a significant past medical history. One child was born with a hypoplastic right heart, a congenital cardiac anomaly in which the right side of the heart is underdeveloped. The typical treatment for hypoplastic heart is a series of heart surgeries completed by three years of age. Children with this condition typically have exercise intolerance; however, this participant's child exceeded the expectations of most health care professionals, is highly involved in competitive sports, and was rarely hospitalized due to the condition.

The majority of the children $(n=8)$ were in treatment for acute lymphocytic leukemia (ALL). ALL is the most common form of childhood cancer and has an $84 \%$ five-year survival rate (American Cancer Society, 2013). Children with ALL go through four phases of treatment: induction, consolidation, central nervous system prophylactic therapy, and maintenance of remission. Most treatment plans for ALL are two to three years in length (American Cancer Society, 2013). Children receive a combination of chemotherapy agents throughout the phases.

Two children were diagnosed with Neuroblastoma. One child was diagnosed at 9-months of age and at the time of the interview was two-years-old. The other child was diagnosed at two years of age, received a stem cell transplant, and recently relapsed. She was five-years old at the time of the interview. Neuroblastoma is a cancer of the nervous system and occurs in children under the age of five (Hockenberry, 2012). Neuroblastoma comprises six percent of all childhood cancer diagnosis, and has a 75\% five-year survival rate (American Cancer Society, 
2013). Treatment for neuroblastoma is dependent on primary site and staging. Treatment usually includes surgery and chemotherapy (Hockenberry, 2012).

An older school-age child had a rare diagnosis of nodular lymphocyte predominant Hodgkin disease. Nodular lymphocyte predominant Hodgkin disease is a type of Hodgkin Disease (American Cancer Society, 2013). Treatment for nodular lymphocyte predominant Hodgkin may include radiation alone or in combination with chemotherapy, depending on the stage of disease. As a whole classification, Hodgkin lymphomas have a $96 \%$ five-year survival rate (American Cancer Society, 2013).

The parents in this study recounted a variety of experiences with their child getting diagnosed with cancer, the time period shortly following diagnosis, and health related problems they interpreted as being associated with their child having cancer or receiving cancer treatment. Two participants shared vivid stories of their child being critically ill and on a ventilator as a result of their cancer treatment. One participant described 28 surgeries his child underwent to treat necrotizing fasciitis. Others spoke about their child refusing to move, speak, or eat while hospitalized for treatment. Almost all parents observed differences between their child's behavior and experiences while undergoing treatment in hospital and upon their return home. Uniformly, they described their children as struggling in the hospital but thriving when discharged to home.

Although parents described the children as not doing well in the inpatient setting, many parents painted a different picture with outpatient therapy. Parents described the Infusion Center, where they received their outpatient therapy, as almost a home away from home. The parents and the children grew accustomed to the outpatient environment and felt comfortable with the nursing and physician care. Some parents stated their child looked forward to going to the 
infusion center. The children enjoyed interacting with the healthcare professionals and getting special treats, such as gifts and the opportunity to play video games.

The research question guiding this study was: How do parents describe their observations and interpretations of the way cancer-related fatigue shapes their child's day-to-day quality of life? The interview questions were informed by the conceptual model of childhood cancerrelated fatigue (Hockenberry-Eaton et al., 1999) and the definition and domains of quality of life in pediatric oncology patients as described by Hinds et al. (2004).

1. How would you describe what a "good day" was like for (child's name) before the cancer?

2. What has having cancer been like for (child's name)? Tell me more.

3. What changes have you noticed in the way (child's name) acts since he/she got cancer? Tell me more.

4. What do you think is causing these changes?

5. What have you noticed about (child's name) energy level since he/she got cancer? Tell me more.

6. How has (child's name) energy level affected the way he/she enjoys time with family and/or friends? Tell me more.

\section{Study Findings}

Seven categories, including five categories with sub-categories, were identified during data analysis. These findings were arranged into three major themes: (a) life before cancer diagnosis, (b) fatigue shaping everyday quality of life, and (c) perspectives of fatigue. The first category identified was the parents' description, of what their child's life was like before the cancer diagnosis; a "snap shot of a good day." Categories two through five refer to 
how the parents described their child's fatigue and how the symptom shaped their child's day-today quality of life. Categories six and seven reflect how parents interpreted their observations and their perspectives of fatigue. The categories with sub-categories are:

Life before Cancer Diagnosis

1. Well Before This...

They were very active

They enjoyed playing with other kids

They were happy

Fatigue Shaping Everyday Quality of Life

2. Real Tired and Stuff

There are days they just lay around

3. Sleeps A Lot and That's Not Normal

At times they completely shut down

4. Wants to Do It But Can't

They aren't as active

They go, go, go and crash

5. They Get Cranky When Tired

Perspectives of Fatigue

6. I Don't Think Its Fatigue

7. I'm Sure Treatment Has A Lot to Do With It

Steroids are the worst 


\section{Life before Cancer Diagnosis}

Category 1: Well Before This...

Universally, the study participants observed marked differences in their children before and after the cancer diagnosis. Play, especially outdoor play, was the overwhelming central topic of parents as they described a good day for their child before his or her cancer diagnosis. Parents of the three older school-age children (10 years and older) discussed their child's participation in organized sports before cancer diagnosis. Parents of younger children described active outdoor play that often included interacting with other children. Within the description of a good day, parents described their children as being happy and having fun. The following are example excerpts of parents discussing life before their child's cancer diagnosis.

Well Before This...

They were very active.

"Normally he would be outside no matter what the weather all day long, playing, riding his bike, riding his scooter, being in the woods.

"He did sports a lot before. He was a very active kid."

They enjoyed playing with other kids.

"Well, um, she was only 2 when she was diagnosed and she seemed like a normal little child. She played and ran around with the other kids and just had fun."

"Well he was very active, constantly running up and down the stairs, running all over the back yard, going up and down the playground equipment, very involved with other kids, wanted to play with other kids, to be around other kids"

"Other kids, she loved being around other kids. Always has. Before this happened and everything, she always told us, come on Mommy, we gotta go to the park, I gotta go make friends." 
They were happy.

"A good day for him would be that he was happy, he would be telling jokes and talking more and up and playing"

"Ahhh...really just her being her normal self, which is usually very happy, she listened very well, she played with her brother and she'd play independently, and really.... I don't know to explain it but ... just a good day, no crankiness, you know on a schedule. You know her nap time was where they needed to be; just very happy would be a good day for her. She always was a happy baby."

Fatigue Shaping Everyday Quality of Life

The following four categories provide the parents' description of their child's fatigue experience and how fatigue shaped their child's day-to-day quality of life. The domains of quality of life were used as a framework for some of the interview questions to tease out the parent's observations and interpretations of their child's quality of life associated with having fatigue from cancer. The domains of quality of life are: usual activities, interaction with others, health status, symptoms, mood, and meaning of being ill.

The term "fatigue" was rarely used by parents. Parents only spoke of fatigue when describing times in which their child was very ill. Most parents used the term "tired" or energy level to describe fatigue symptoms. Their observations often lumped "being tired" with other symptoms such as vomiting, nausea, and moodiness. It was difficult for parents to isolate and describe the discrete symptom of fatigue.

Some of the parents stated that their children sometimes slept for hours or even days. Two parents described their child's behavior as "shutting down." "Shutting down" meant that the children did nothing for themselves; they did not eat, move, or talk. Clearly, these behaviors 
impacted interactions with family and peers, and interfered with age-appropriate activities, play, and school involvement. There were times the child's tiredness and drastic change in energy level signaled something was wrong and as one participant shared, it "scared her to death." She knew by the child's energy level something was terribly wrong, but her fears were not initially heard by healthcare professionals. In this case, the change in energy level was indicative of neutropenia that resulted in an 8-day hospitalization once diagnosed.

\section{Category 2: Real Tired and Stuff}

The second category and sub-category reflect the parents' description of the intersection of fatigue and domains of quality of life, particularly the domain of symptoms. Parents rarely used the term "fatigue" or interpreted the symptoms that the child was experiencing as fatigue. Rather, parents described their child as "being tired" or "lying" around and often clustered decreased energy levels with other symptoms such as vomiting, nausea, and moodiness. The following are representative quotes of parents' descriptions of times when their child experienced "tiredness", often associated with other symptoms.

\section{Real Tired and Stuff}

"I mean other than, like I said, after the treatments for the rest of that day and part of the next she is kinda tired and wore out and her belly is upset and stuff"

"He goes [to school] Monday, Wednesday, Friday half days. Doing good. Tried half days every day but he would get so sick if he went two days in a row so we just cut two days out. He would get tired enough he would vomit he would be so exhausted he would come home and sleep and not wake up for hours and hours."

"He would get sick and he would be kinda like real tired and stuff, but then like I said, he still wanted something to eat." 


\section{There are days they just lay around.}

"He goes out for a little bit but he gets real tired and comes back in. And some days he just can't even get up."

'I mean, there are days she doesn't want to, we'll say let's go bye-bye. No I stay home and she just lies around."

\section{Category 3: Sleeps A Lot and It's Not Normal}

The third category and sub-category reflect the parents' description of the intersection of fatigue and quality of life, particularly the domain of health status. Health status is described as the receiving of "treatment-related news" and being able to perform self-care activities (Hinds et al,. 2004, p. 765). Parents reserved the term fatigue for when the child was seriously ill, for example upon initial diagnosis, times of hospitalization, or an indication of neutropenia. Parents discussed being very frightened over their child's changed energy level, knowing the change indicated a change in health status. The following category and sub-category represent when parents described situations in which their child's energy level indicated something was terribly wrong.

\section{Sleeps A Lot and It's Not Normal}

"Oh and I'll mention too the only time we noticed him being lethargic and sleeping longer, and I've called them when it happens because it scared me to death because he's never done that before, is when his blood has been low, it's like a sign that he needed a blood transfusion or when he's on the steroids. There was a time we had been hospitalized a few weeks ago for about 8 days, I don't know if you knew about that but he got a blood transfusion and a platelet transfusion and like a week before that, before we were hospitalized, I called like a hundred times a day and I'd be like he's sleeping a 
lot, he just does not do this. He's just very sleepy and that's what it was. That's the only time."

"Well, um, she was only 2 when she was diagnosed and she seemed like a normal little child. She played and ran around with the other kids and just had fun. The last few weeks before she was diagnosed we noticed a decrease in her activity. She slept a lot."

At times they completely shut down.

“Everything. She quit eating. She quit drinking. Everything. Quit playing. She didn’t want to talk to nobody. She slept most of the time."

"The only time that she changed is when we are in the hospital for long periods of time. For example, when we got her bone marrow transplant. We were up there for 3 months and she completely shut down on me. She didn't want to do nothing. She didn't want to walk. She didn't want to play. All she wanted to do was lay there until they let her out of there."

"I'm not getting any better months and months of that that he did not want to live or do anything he wouldn't hardly get up off the couch. He just...he lived on the couch for nearly a year. His eleventh year of life was pretty much on the couch"

\section{Category 4: Wants to Do It But Can't}

The parents often used outdoor play and organized sports to gauge their child's energy level. All three parents of older school age children (10-12 years of age) discussed changes in their child's ability to participate in organized sports. Parents of younger children spoke about the child as having low energy when the child was not engaging in active outdoor play. Several parents described a battle between the child's will and physical body. These parents stated that their child had a strong will to keep doing or pushing on, but their child's body would not 
cooperate. Two of the three parents of children 2 years of age and younger depicted their child as being "wired" and then crashing from exhaustion. This phenomenon was exclusive to parents of very young children.

As previously stated parents rarely used the term "fatigue," and had difficulty isolating fatigue symptoms from other symptoms. Similarly, parents in this study never used the term "fatigue" when describing a change in the child's usual activities from fatigue, but referred to the changes as a decrease in "energy" or "activity" levels. The following category, including two sub-categories, provides the parent's description of how their child's fatigue symptom interfered with usual activities, and at times, interaction with others.

\section{Wants to Do It But Can't}

"The will was there. You know, he wanted to do it, so the will is there to continue stuff like that. There were a couple of games that he was like, you know, coach, I can't play this inning and they would put a substitute in and play, but usually that was really close to the treatment schedule. You know, those first couple of days he is really close. There was a Saturday game. We got done and we went home on Friday and there was a Saturday game that he really wanted to go to, but he was just wiped."

"He wants to go up those stairs, he wants to go up that slide, it's just he just can't do it as quickly as he used to because he just physically can't."

They aren't as active.

"I could say that, you know, maybe he wasn't as active as most boys his age, like going outside in the heat and stuff, he just didn't feel like doing. We have a swimming pool and there were a lot of times where he would only be out with us for a little bit and he would ask if he could just come back in." 
"Now as far as we were talking about the other normal part of his day, which used to be being very active, he isn't as active"

“Then she would get up and she would watch TV, but she wasn't as active and she still isn't."

They go, go, go and crash.

"There were nights that we stayed up all night long, and then she would just crash. She would go, go, go and then crash, and go, go, go and then crash."

"My son plays baseball and my daughter cheers. She'll get in there and play in the field. When she's done, she's done. When these kids want to keep playing, no, stop she's done."

"Cause he would be playing hard and then all of a sudden he'd be like "night, night" and grab our hands and take us in there and he'd sleep for a long time."

\section{Category 5: They Get Cranky When Tired}

Parents described a change in their child's behavior as he or she gets tired. Some parents reported a ripple effect of tiredness, crankiness, and unwillingness to play or interact with others. Other parents discussed their child's altered mood but could not always identify the cause. This was especially true of parents with very young children (2 years and younger). These parents described their children as being very angry, aggressive, or not wanting to play with other children. Some parents noted changes in their child's relationships with their well siblings before and after the cancer diagnosis. Other parents identified major changes in their child's mood and their ability to interact with others when taking steroids. The following category and subcategories represent the parent's descriptions of how fatigue intersects with their child's mood. They Get Cranky When Tired 
"Yes, there are times when she is very cranky and like they want to play."

"And if she doesn't get her nap, she's exhausted, she gets very cranky."

"Just being tired and being a little cranky, you know, has been part of it, but for the most part, he is such a good kid."

"Now if I don't let her go to sleep like right away, then, yeah her mood will change."

\section{Perspectives of Fatigue}

\section{Category 6: I Don't Think It's Fatigue}

There appears to be a discontinuity between how parents described and how they interpreted the ways in which cancer-related fatigue shaped their child's day-to-day quality of life. Only two parents reported fatigue as a problematic symptom that negatively impacted dayto-day quality of life. Of interest, these comments came from the parents of the youngest and oldest children in the study. The majority of parents in this study stated their child did not experience fatigue and that their child's "tiredness" did not have a negative impact on quality of life. Yet, all parents described characteristics of fatigue and most parents described situations in which fatigue negatively impacted their child's quality of life. This gap in the ways that parents describe and interpret the links between fatigue and quality of life may indicate that the term fatigue is not well understood or that fatigue represents something much different to parents than it does to the researcher. The researcher and parents' perspective of childhood cancer-related fatigue may differ due to the researcher's clinical experience and knowledge gained from reading childhood cancer-related fatigue literature. Most parents do not have clinical experience in pediatric oncology nor have they read childhood cancer-related fatigue literature. Parents' understanding of childhood cancer-related fatigue is through caring for and loving a child with 
cancer. Therefore, their understanding of fatigue may be quite different than that of the researcher and other health care professionals because the care experience is different.

The previous categories provided the parents' description of fatigue and how fatigue impacted five domains of quality of life. Parents reported their child's fatigue symptoms are influenced by health status and associated with other symptoms, and that fatigue symptoms impacts usual activities, mood, and interaction with others. Yet, parents interpreted these changes much differently. Most parents denied that their child experienced fatigue and commented that they were surprised about how normal things remain. It appears parents are speaking to a "new normal" for their child; this is just something else they have to get through to get their child well. Parents believed, unequivocally, that cancer treatment caused the changes in their child, and reported that steroids caused major problems in the children's relationships, moods, and sleep patterns. The following two categories and sub-categories provide parents' interpretation of how fatigue has shaped their child's day-to-day quality of life.

\section{Don't Think Its Fatigue}

'I don't think it's fatigue. When you say fatigue, you mean like mentally tired, don't want to be active. Right?”

"Definitely not, he's definitely not wiped out."

"She's just been an amazing trooper the whole time... She gets up every morning around 7 and has a normal day. There's not a whole lot different now than before."

"[I] don't think so (his tiredness compared to other child). I think it is about the same." "See how, I mean look at him, look how horrible he looks, but listen to how excited he is. So tell me that's fatigue." 


\section{Category 7: I'm Sure Treatment Has A Lot to Do With It}

Parents clearly identified cancer treatment as the source of many problems their children experience. Chemotherapy, hospitalization, procedures, appointments, and long commutes for treatment were associated with making the child feel sick and causing the child to be tired, moody, nauseous, and achy. Again, several parents did not interpret the child as having fatigue but felt their children were experiencing side effects of therapy that was making them physically unable to "do." For example, one parent stated the medications made the child hurt therefore the child limits his or her activity due to the pain rather than a lack of energy. Another parent described their child as having a lack of energy when taking steroids. She interpreted that this lack of energy was due to gaining weight and "having a heavy feeling."

Steroids were repeatedly identified for causing major side effects and interpreted as "one of the worst things." Parents described the effects of steroids on their child's energy level differently. Some parents reported their child was very hyperactive on steroids, at times uncontrollable. Other parents reported their child as feeling tired and not wanting to do much when taking steroids. Some children experienced severe side effects from steroids, including neuropathy, which caused one child to be confined to a wheelchair for a several months. Parents' interpreted steroids rather than fatigue as being the cause of changes in their child's mood. Some parents described mood changes that were severe and negatively impacted interactions with others. The following category and sub-category represents parents' interpretation of what is causing many of the changes in their child's life. 


\section{I'm Sure Treatment Has A Lot to Do With It}

"It's the medication that just makes him hurt. I don't think it makes him even tired, I think it makes him achy or his joints hurt. He doesn't tell us. I don't think it affects his energy at all."

"She is kinda down for the rest of that day (when receiving chemotherapy) and part of the next, but about mid-day the next day, she is ready to go play and run around and be a normal little 3-year-old."

"I know that when she has her procedures I know that makes her tired, when she has the different procedures and gets the propofol. Even when the propofol is out of her system she still is very tired for the rest of the day, but the next day she is completely back to normal."

Steroids are the worst.

“With her I haven't noticed any energy level going down except for when she's on the steroids. The steroids have got to be one of the worst medicines for us. That is probably the biggest pain."

"And they are very hard to console or talk to or calm them down. It's like you put that (steroids) in their body and they're everywhere."

"On the steroids, yea, and I think part that is part of the moodiness is she can't get out and play because she feels like she can't move. She's got that heavy feeling."

"He always took his moods out on his sister. I mean when he was on the steroids, you could guarantee for her to stay away because for some reason he was the nastiest to his poor sister." 


\section{Maintenance of Rigor}

The investigator of this study maintained the trustworthiness of the findings by adhering to the principles of credibility, dependability, and transferability. Credibility refers to the focus of the research and "how well data and processes of analysis address the intended focus" of the study (Graneheim \& Lundman, 2004, p.109). The researcher of this study used the following measures to achieve credibility: (a) utilized the expertise of the dissertation chair and committee during the development phase of this research, including decisions related to study design and participant selection; (b) used portions of interviews that related to childhood cancer-related fatigue and the six domains of quality of life; (c) sought agreement among dissertation chair and committee members related to the findings of this study; (d) reviewed the developing categories using conceptual and empirical findings; and (e) used direct quotes to support the abstraction of categories.

Dependability is the second aspect of trustworthiness. Dependability is "the degree to which data change over time and alterations made in the researcher's decisions during the analysis process" (Granheim \& Lundman, 2004, p. 110). The following steps were employed to ensure dependability: (a) used semi-structured questions to guide interviews, ensuring all areas were covered; and (b) maintained open communication with dissertation chair.

Transferability is the final aspect of trustworthiness of qualitative research findings. Transferability can be achieved by properly and thoroughly discussing research methods and reporting findings. The following measures were used when reporting findings from this study: (a) provided a detailed report to facilitate a clear understanding by readers; (b) demonstrated a link between results and the data by including representative quotes; and (c) fully discussed the implications of the findings for nursing practice, teaching, and research. 


\section{Conclusion}

Chapter four discussed the findings for this qualitative study that described parents' observations and interpretations of the way cancer-related fatigue shapes their child's day-to-day quality of life. The researcher identified seven categories and provided direct quotes to support the abstraction of categories. The study findings reveal contradictions in how parents describe and interpret cancer-related fatigue when talking about how the symptom shapes their child's everyday quality of life. The majority of parents in this study stated their child did not experience fatigue and that their child's "tiredness" did not have a negative impact on quality of life. Yet, all parents described characteristics of fatigue and most parents described situations in which fatigue negatively impacted their child's quality of life. This apparent contradiction may indicate that the term fatigue is defined, perceived, understood, and interpreted differently by the parents and the researcher and other health professionals. At times, fatigue also represented a "danger signal" to parents and some participants felt as though health professionals did not hear them when they expressed their concerns about changes in their child's energy levels. The implications of the thematic findings of the study are discussed more fully in chapter five. 


\section{Chapter 5}

\section{Discussion}

The purpose of this qualitative descriptive study was to gain the parents' perspectives, descriptions, and interpretations of how cancer-related fatigue shapes their child's (1-12 years of age) day-to-day quality of life. This study used the concept of fatigue and six domains of quality of life in pediatric oncology patients as a framework that guided data collection, analysis, and discussion of the findings. The following question was answered: How do parents describe their observations and interpretations of the way cancer-related fatigue shapes their child's day-to-day quality of life? As noted in the previous chapter, findings of this study were arranged by three major themes: (a) life before cancer diagnosis, (b) fatigue shaping everyday quality of life, and (c) perspectives of fatigue. Findings were grounded by the domains of quality of life in pediatric oncology patients. The thematic categories and corresponding sub-categories discovered were as follows:

Life before Cancer Diagnosis

1. Well Before This...

They were very active

They enjoyed playing with other kids

They were happy

Fatigue Shaping Everyday Quality of Life

2. Real Tired and Stuff

There are days they just lay around

3. Sleeps A Lot and That's Not Normal At times they completely shut down 
4. Wants to Do It But Can’t

They aren't as active

They go, go, go and crash

5. They Get Cranky When Tired

Perspectives of Fatigue

6. I Don't Think Its Fatigue

7. I'm Sure Treatment Has A Lot to Do With It

Steroids are the worst

The findings of this study contribute to nursing science and address knowledge gaps in the childhood cancer-related fatigue literature by describing parents' perspectives of how fatigue from cancer shapes their child's day-to-day quality of life. Furthermore, as one of the very few studies of cancer-related fatigue to include children under the age of six, the findings of this study establish a basis for understanding the younger child's fatigue experience. The major findings of this study are: (1) differences exist in how parents, researchers, and clinicians talk about childhood cancer-related fatigue and make sense of how the symptom does or does not shape a child's everyday quality of life, and (2) parents of very young children $(<3$ years of age; $\mathrm{n}=2$ ) describe different characteristics and manifestations of fatigue than parents of older children. The purpose of this chapter is to present a thematic summary of the findings in relation to the concept of fatigue and developmentally appropriate quality of life before and after cancer diagnosis. The findings are discussed within the context of relevant theories, research, and implications for nursing practice, education, and research. 


\section{Conceptual Framework}

This study was grounded by the conceptual understanding of childhood cancer-related fatigue (Hockenberry \& Hinds, 2000) and quality of life in pediatric oncology patients (Hinds et al., 2004). The conceptual definition of fatigue and six domains of quality of life in pediatric oncology patients identified by Hinds et al. (2004) were used as a framework for formulating interview questions, developing codes, and organizing categories during data analysis. The following section includes an overview of fatigue and quality of life concepts, discusses how the researcher used the concepts of fatigue and quality of life to plan and implement this study, and provides a discussion on how the findings of this study support the conceptual understanding of fatigue and provide new knowledge in how fatigue from cancer shapes the child's quality of life.

The conceptual definition and six domains of quality of life in pediatric oncology reported by Hinds et al. (2004) were used in this study. Using data obtained from interviews of school-age children and adolescents with leukemia, Hinds and colleagues developed the following definition: "an overall sense of well-being based on being able to participate in usual activities, to interact with others, and feel cared about, to cope with uncomfortable physical, emotional, and cognitive reactions, and to find meaning in the illness experience" (p. 767). Additionally, Hinds et al. identified the subsequent six domains of quality of life in pediatric patients: "usual activities, social/family interaction, health status, symptoms, mood, and the meaning of being ill” (p. 767).

The conceptual understanding of fatigue is remarkably similar to quality of life in pediatric oncology patients, each having physical, mental, and emotional components. Hockenberry and Hinds (2000) generated and reported the first and most widely cited definitions of childhood cancer-related fatigue. Cancer-related fatigue in children is defined as being acute, 
episodic, or chronic; causing mental and physical symptoms; impacting normal functioning; having environmental and treatment-related influences; and, being alleviated by rest and distraction (Hinds, Hockenberry-Eaton, Quargneti et al., 1999; Hockenberry-Eaton et al., 1999; Hockenberry-Eaton et al., 1998). Childhood cancer-related fatigue "can result in difficulties with play, concentration, and negative emotions, most typically anger and sadness" (HockenberryEaton et al., p. 9). Thus, fatigue impacts the child's (a) normal activities, such as play, (b) interaction with others, and (c) mood. These areas parallel usual activities, social/family interaction, and mood domains of quality of life in pediatric oncology patients as defined by Hinds and colleagues (2004). Consequently, fatigue has a great potential to influence the quality of life of a child living with cancer.

The investigator of this study used the definition of fatigue and domains of quality of life as a framework to analyze parents' descriptions and interpretations of how fatigue from cancer shapes their child's day-to-day quality of life. The intersection of fatigue and quality of life was captured during data analysis by the researcher highlighting all sections of text that referred to any of the six domains of quality of life and then highlighting any of the text that referred to the concept of fatigue. Thus, three areas of the interviews were highlighted and coded: fatigue, quality of life, and the intersection of fatigue and quality of life. This approach afforded the investigator the ability to capture and better understand parents' perspectives of how childhood cancer-related fatigue influenced their child's day-to-day quality of life.

The findings of this study support existing literature related to the concept of fatigue and provide new insight into how parents describe and interpret the impact of fatigue on their child's day-to-day quality of life. Parents described their child with cancer as having varied degrees of fatigue and experiencing mental, physical, and emotional symptoms as a result of fatigue. 
Parents recalled times when their child's energy level prohibited everyday functioning and changed the child's usual activities. As evident in the following statement, "I mean, there are days she doesn't want to, we'll say let's go bye-bye. No I stay home and she just lies around." Consistent with the literature (Hinds, Hockenberry-Eaton, Quargneti et al., 1999; HockenberryEaton, Gilger et al., 1999; Hockenberry-Eaton et al., 1998; Hockenberry \& Hinds, 2000), participants identified treatment factors and hospital and clinic environments as contributing factors for their child's fatigue. Parents described and interpreted resting, engaging in quiet activities, and changing schedules as methods to help the child regain energy levels. These interventions for alleviating fatigue are consistent with the conceptual understanding of fatigue and recognized as alleviating factors throughout the childhood cancer-related literature (Chiang et al., 2009; Hockenberry-Eaton et al.; Hockenberry \& Hinds; Wu et al., 2009). Yet, true to the literature (Chiang et al.; Davies et al., 2002; Gibson, Mulhall et al., 2005; Hockenberry-Eaton et al.; Woodgate et al., 2003; Wu et al.), the term "fatigue" was rarely used by parents. As previously reported (Chiang et al.; Davies et al.; Hinds, Hockenberry-Eaton, Gilger et al.; Hockenberry-Eaton et al.; Wu et al.), participants used the term "tired" or "energy level" to describe fatigue symptoms. Furthermore, all parents in the study described characteristics of fatigue in their child's daily life, yet the majority of parents $(n=9)$ denied that their child experienced fatigue and stated they were surprised by how "normal" life remained.

This incongruity between parents' descriptions and interpretations of childhood cancerrelated fatigue and how the symptom shapes their child's day-to-day quality of life was uncovered by asking parents to provide a "snap shot" of their child before cancer. Overwhelmingly, parents in this study referred to play, especially active outdoor play, in describing a good day for their child prior to cancer diagnosis. Play is the work of children and is 
vital to normal child intellectual, psychosocial, and physical development (Hockenberry \& Wilson, 2011). Parents described their child's play as active, interactive, and fun. All parents provided a vivid picture of their child happily playing with other children and/or siblings. Clearly, participants' descriptions of their children before cancer are consistent with positive quality of life indicators. The description of a good day provided insight to parents' perspectives of good quality of life for their child prior to cancer. The data gathered were used as a standard and helped in identifying changes following cancer diagnosis. Parents' descriptions of their child's good day prior to cancer related to the following domains of quality of life: usual activity, mood, and social/family interaction. Parents described their children before cancer as engaging in active play, being in a good mood, and easily interacting with others. Their children were happy, smiling, talking, joking, and having fun. Before the cancer diagnosis parents recalled their children as wanting to play with siblings and other children. Following cancer diagnosis parents described fatigue characteristics that impacted their child's usual activities, mood, and interaction with others. Universally, the study participants described marked differences in their children before and after cancer diagnosis signifying a disruption of normal everyday functioning of the child with cancer and fatigue shaping day-to-day quality of life. However, the majority of parents interpreted these changes much differently than what the researcher anticipated. The findings of this study expose differences in how parents and health care providers communicate and think about childhood cancer-related fatigue.

\section{Research Findings and the Literature}

Parents reported conflicting descriptions and interpretations of how fatigue from cancer shaped their child's day-to-day quality of life. Parents described their children with cancer as (a) not being as active as before the cancer diagnosis and as compared to other children of similar 
age, (b) becoming moody when tired, often contributing to problems when interacting with siblings and other children, and (c) having characteristics of fatigue when their child was experiencing other symptoms of cancer and cancer treatment. However, parents interpreted these changes in usual activities, social/family interaction, and mood, all domains of quality of life, much differently than expected. Despite these descriptions, most parents $(n=9)$ did not interpret fatigue as negatively impacting their child's day-to-day quality of life and expressed surprise at how normal things remained.

The following sections will discuss the major findings of this study and link the findings to empirical research. The research findings and the literature will be organized using the two major findings of this study as headings (a) differences exist in how parents, researchers, and clinicians talk about childhood cancer-related fatigue and make sense of how the symptom shapes the child's day-to-day quality of life, and (b) parents of very young children $(<3$ years of age; $n=2$ ) describe different characteristics and manifestations of fatigue.

Differences exist in how parents, researchers, and clinicians talk about childhood cancer-related fatigue and make sense of how the symptom shapes the child's day-to-day quality of life

The study findings reveal incongruities in how parents described and interpreted cancerrelated fatigue when talking about how the symptom shaped their child's everyday quality of life. This gap may be explained by (a) parents find it difficult to "deconstruct" their child's symptom experiences, (b) parents develop a "new normal" for their child with cancer, and (c) fatigue and/or quality of life represent something much different to parents.

Parents find it difficult to "deconstruct" their child's symptom experiences.

The parents in this study clustered fatigue as either being a part of or linked to other symptoms or experiences, such as nausea, moodiness, and/or cancer treatment rather than the 
disease. Consistent with the literature (Chiang et al., 2009; Davies et al., 2002; Gibson, Mulhall et al., 2005; Hockenberry-Eaton et al., 1998; Woodgate et al., 2003; Wu et al., 2009), parents in this study rarely used the term fatigue and the majority of parents in this study $(n=9)$ did not feel that their child experienced childhood cancer-related fatigue. Yet, all participants described characteristics of fatigue that impacted their child's day-to-day quality of life. According to a previous qualitative study, families and children with cancer viewed symptoms as more than a singular event but as multidimensional experiences, finding it difficult to "deconstruct overall symptom experiences" (Woodgate et al., p. 804). This may explain why parents described characteristics of fatigue but did not interpret it as being a discrete symptom. Parents may not isolate fatigue as a symptom, but interpret that their child's lack of energy is a result of something else.

Parents develop a "new normal" for their child with cancer.

Parents' pre-diagnosis "snapshot" of their child's activities and quality of life was much different than their descriptions of life following cancer diagnosis. Parents described changes in their child's energy level that negatively impacted usual activities, interactions with others, and mood, thereby impacting quality of life. Yet, parents interpreted things were relatively "normal" and did not think fatigue negatively impacted their child's day-to-day quality of life.

Following a diagnosis of cancer, parents no longer view the child's life in the framework of a "healthy" child, but of a child with cancer (Woodgate et al., 2004). Findings of this study support previous research (Woodgate et al., 2004) suggesting parents develop a "new normal" for their child diagnosed with cancer. This "new normal" may also assist in explaining the discontinuity between parents' descriptions and interpretations of how cancer-related fatigue shaped their child's day-to-day quality of life. Parents and children with cancer come to expect 
certain symptoms as part of everyday life (Woodgate et al., 2003). These everyday symptoms or subtle symptoms are often welcomed by parents because they symbolize that the child is not "too sick" and the child is establishing some type of normalcy post-cancer diagnosis (Woodgate et al., 2003). This "new normal" where quality of life is not what it was before the cancer is a significant improvement over the child's experiences in the hospital during initiation of treatment or when they were critically ill. It is reasonable to think parents' expectation of their children's day-to-day quality of life is altered when framing a "new normal" for their children with cancer. As part, parents view symptoms associated with cancer treatment as inevitable in battling and defeating cancer.

Within the "new normal" parameters of a child with cancer, parents may not expect their child to participate in activities at the same intensity as they did before their cancer diagnosis. Several participants described their child as having a "will" to carry on with typical activities, but their bodies would not cooperate. To the author's knowledge this has not been reported in previous studies related to childhood cancer-related fatigue and is a valuable finding in understanding parents' interpretation of how fatigue shapes day-to-day quality of life. Parents may interpret their child is not experiencing fatigue because the child has a desire or will to play or remain in sports. This perspective is evidenced by the following statement of a participant, "When you say fatigue, you mean like mentally tired, don't want to be active, Right?" This parent understood fatigue to be a cognitive in nature and defined it as a child lacking 'interest" in usual activities. The parent did not think her child was experiencing fatigue, but he was just physically unable to "do" his normal activities. 


\section{Fatigue and/or quality of life represent something much different to parents than the} researcher.

Symptoms from cancer treatment may represent something much different to parents than to researchers and clinicians. Parents described changes in their child's day-to-day quality of life due to fatigue. Yet, most parents did not interpret "fatigue" as negatively impacting their child's day-to-day quality of life. Rather, they attributed the quality of life impact to treatment, thereby distinguishing between the cancer and its treatment. It is not clear from this study what psychological factors associated with this finding might be at play, but it might be that it is a protective mechanism that helps parents to reconcile subjecting their child to the often devastating effects of treatment during the initial diagnosis and treatment phases and hospitalizations. Otherwise, parents stated things were pretty normal. This may represent that parents find it easier or more palatable to attribute fatigue to the cancer treatment as opposed to the cancer itself, because the latter notion might be symbolic of disease progression. Woodgate \& Denger (2003) found families and children fight the symptoms because it is "more tangible and less frightening" than fighting cancer (p.483). Parents may view subtle symptoms associated with cancer treatment as needed to cure their child of cancer and used as an indicator that their child is "getting better" because the symptoms are less severe than previously experienced.

The majority of participants only identified and recognized fatigue as negatively impacting their child's quality of life when the child was experiencing extreme fatigue that corresponded to a change in health status. Consistent with the typologies of childhood cancerrelated fatigue identified by Davies et al. (2002), some participants described their child as "shutting down" while hospitalized. One parent recounted pulling her child in a wagon around the hallways of the hospital because her child was too tired to walk and worrying because the 
child refused to eat or talk. Several parents only recognized fatigue as negatively impacting their child's quality of life during these "shut down" events. Parents may use a frightening event such as this to not only frame their understanding of fatigue but to inform their perspective of quality of life for their child with cancer.

A parent's perspective of their child's quality of life may be influenced by several intrinsic and extrinsic factors. Eisner \& Morse (2001) discuss that parents' perspective on their child's quality of life is informed by "the burden of care giving, and their own mental health, well-being and concerns" (p. 356). The primary objective of understanding quality of life is to assist the patient in restoring "an optimal level of wellness as defined by the patient" (Hinds et al., 2006, p. 27). The definition and domains of quality of life for a child with cancer (Hinds et al., 2004) were developed through interviews with school-age children and adolescents with cancer. Parents' perspectives of quality of life for their children with cancer may be much different than that of school-age children or adolescents with cancer. This emphasizes the need to personalize quality of life assessment for each family and child with cancer due to individuals' unique perspectives of health and illness. Open communication among health care professionals, parents, and children with cancer are important in understanding and appropriately addressing actual concerns of families and patients (Hinds et al., 2006).

Cultural differences between health care professionals and families caring for a child with cancer may pose a barrier to quality patient care. Pediatric oncology health care providers speak a different language, understand health much differently than lay population, and have preconceived beliefs stemming from formal education and practice (Fernandez \& Fernandez, 2011). The findings of this study suggest fatigue represents something much different to parents than to the investigator and possibly other health care professionals. This difference may be 
explained by a cultural gap among the provider, patient, and family. The clinician could reconcile part of these differences by: identifying his or her own ethnocentrisms (Fernandez \& Fernandez, 2011), recognizing each family member as an important part of providing care to the child with cancer, maintaining open communication, and recognizing parents as experts in caring for their child with cancer. It is imperative that clinicians, children with cancer, and their families all speak and understand the same "language" to adequately assess and appropriately manage fatigue.

Parents are the experts of their children and can provide a rich description and insight into their child's health and illness experience. Parents are more likely to provide reports that details series of events rather than grounding reports on most recent events as do most children (Hinds, 2010). This may help to explain why children consistently report higher functioning and better quality of life than parents (Parsons, 2012). It is plausible that parents' reports of their child with cancer quality of life are lower because parents see the "whole picture." Thus, this punctuates the importance of gaining parents' report of fatigue symptoms, clarifying the "language" used between healthcare provider and parent, and seeking quality of life reports from the parent(s) and, when developmentally appropriate and linguistically possible, the child with cancer. Multiple informants can provide a much better understanding of the "whole picture" of quality of life in children with cancer (Eisner et al., 2001; Hinds; \& Parsons).

Parents of very young children ( $<3$ years of age; $n=2)$ describes different characteristics and manifestations of fatigue

Childhood cancer-related fatigue is different both in terms of its manifestations and its impact across age groups (Hockenberry-Easton, Hinds, Alcoser, O’Neill, et al., 1998; Chiang, Yeh, Wang, \& Yang, 2008) and such was the case with this study's participants. Developmental 
level was an important factor in how parents' described and interpreted how fatigue from cancer shaped their child's day-to-day quality of life. In this study, parents of very young children provided different characteristics when describing their child's energy level.

Exclusively, parents of very young children (2 years and younger) depicted their child as being "wired" and then crashing from exhaustion. This "go, go, go and crash" phenomenon may be partially explained by the child's developmental level and lack of linguistic ability. The toddler years are "a time of intense exploration of the environment" (Hockenberry \& Wilson, 2011, p. 609) and a time that the child is trying to achieve autonomy (Hockenberry \& Wilson). Toddlers instinctively participate in very active play. This may explain why parents described their toddlers with cancer as being "wired" and on the go but then crashing from exhaustion. The toddler engages in active play, but lacks the linguistic and cognitive abilities to communicate feeling fatigued and needing to rest. Toddlers continue to play until they succumb to exhaustion. While this is normative behavior among toddlers in general, in this sample, parents described it as being extreme and not normal for their toddler. In some cases, their child's behavior was different from the anticipatory guidance provided by the health care provider related to what the parents could expect during treatment and/or procedures. In two cases, the nurse told the parents to expect their child to be sedated after a procedure and the child had a paradoxical reaction to the medication and was "wired."

One participant recalled when a change in her child's energy level "scared her to death" and her concerns were not heard by health care professionals. The mother described a day when her toddler would play really hard but would abruptly stop and grab her hand and say "night, night." After several hours of sleep the cycle of "go, go, go, crash" was repeated, signaling to the parent that there was something terribly wrong. After repeated unsuccessful attempts to alert 
health professionals of her concerns, the child was eventually found to have neutropenia and was hospitalized for eight days. Given the tendency of health professionals to assess other cancerrelated symptoms such as nausea and pain but to overlook or minimize the symptom of fatigue (Yilmaz et al., 2010; Gibson, Garnett, Richardson, Edwards, \& Sepion, 2005), this finding begs the question: How often is treatment delayed or early warning signs of potentially serious complications overlooked due to inadequate assessment of and/or miscommunication about cancer-related fatigue?

Parents of younger children also noted changes in their child's relationships with his or her well siblings before and after the cancer. Before cancer, the younger children were described as playing well with other children and being happy. After the cancer diagnosis, these same children were described as being very angry, aggressive, or not wanting to play with other children. One parent noted that their child was very sweet and kind to adults but would become easily agitated with other children. This parent described her child's behavior as significantly changing, "for the worst." Although parents could not always identify the cause of their child's anger, aggression, or unwillingness to play with others, at times, being tired was recognized as a cause. Thus, indicating fatigue in toddlers with cancer may shape the child's day-to-day quality of life by negatively impacting mood, usual activities, and interactions with others. The findings of this study provide new insight into the experience of cancer-related fatigue in very young children, an understudied patient population in this area of research.

This study supports previous findings in the literature and offers new findings that add to the childhood-cancer related fatigue body of knowledge. The main finding from this study suggests that differences exist in how parents, researchers and clinicians talk about cancerrelated fatigue and make sense of how the symptom shapes the child's everyday quality of life. 
These differences may be explained by (a) parents difficulty "deconstructing" their child's symptom experiences, (b) parents developing a "new normal" for their child with cancer, and (b) fatigue and/or quality of life representing something much different to parents than the researcher. Additionally, parents of very young children provided unique descriptions of their child's energy level. In the following sections the investigator will offer how the findings from this study can be used in nursing practice.

\section{Implications for Nursing}

\section{Practice}

The knowledge gained from this study improves our understanding of the family and child's experience of childhood cancer-related fatigue and how the symptom shapes the child's day-to-day quality of life. In a previous study aimed at describing how health care professionals define and assess childhood cancer-related fatigue, all respondents reported that they assessed fatigue by listening to the patients' statements regarding feeling tired (Yilmaz et al., 2010). Waiting for patients to discuss concerns of "feeling tired" may or may not uncover the presence or severity of fatigue among pediatric cancer patients. According to Wu and colleagues (2009), children (ages 7-18 years) with cancer often acknowledged that they experienced cancer-related fatigue but did not share concerns with family members or healthcare professionals because they assumed nothing could be done to improve the symptom. Moreover, parents reported not discussing concerns about their child's fatigue with a healthcare professional because they did not want to burden the professional with what is thought to be an inevitable symptom (Gibson, Garnett, et al.; Hinds \& Hockenberry-Eaton, 2000).

The majority of parents in this study denied that their children with cancer experienced fatigue; however, characteristics of fatigue were embedded within the parents' descriptions of 
their child's day-to-day life. The findings of this study supports Woodgate et al. (2003) and their suggestion that pediatric oncology health providers should first focus on the child's overall "feeling state" before attempting to assess singular symptoms (p. 813). The investigator of the current study suggests health care providers should ask parents and children to provide a description of a typical day in the past week, especially a description of the child's everyday life using the domains of quality of life as a guiding framework. Findings from this study suggest parents use outdoor play and organized sports to gauge their child's energy level. Therefore, health care providers might glean important information by focusing on the child's behavior while assessing and then discerning what parents are actually saying. This can be accomplished by asking probing questions and listening attentively to the meaning behind the words parents use. Clinicians can improve communication by asking parents to discuss what type of play their child engages in and how play compares to pre-diagnosis or well siblings at the same age. This detailed description of a typical day could assist health care providers in gaining a greater understanding of the family's and child's experience with cancer and assist in identifying fatigue symptoms experienced during day-to-day life. Once fatigue is identified, clinicians can then devise a proper treatment plan to help manage fatigue symptoms and/or providing anticipatory guidance and information about what is known about the causes and alleviating factors of fatigue among children with cancer.

This study found differences between parent's descriptions and interpretations of how fatigue from cancer shaped their child's day-to-day quality of life. The majority of parents in this study stated their child did not experience fatigue and that their child's "tiredness" did not have a negative impact on quality of life. Yet, all parents described characteristics of fatigue and most parents described situations in which fatigue negatively impacted their child's quality of life. 
This gap may be a result of parents developing a "new normal" for their child with cancer. The parents "new normal" for their child with cancer may include everyday symptoms that are not recognized or poorly managed because parents considered symptoms normal and an inevitable part of cancer and cancer treatment. This finding reinforces the need for health care providers to: (a) assess for fatigue by gaining a detailed description of the family and child's day-to-day life; (b) seek parents" understanding of the term "fatigue"; (c) identify fatigue symptoms that the child with cancer may be experiencing; (d) provide the family and child with education about fatigue; (e) encourage the family and child with cancer to discuss concerns related to fatigue; and (f) evaluate pediatric cancer patients for fatigue and other symptoms during each health care encounter with the family and child. Additionally, clinicians need to have open communication with the parents and child with cancer about their meaning and understanding of cancer and its treatment, and how they are coping in day-to-day life.

Unfortunately, clinicians do not adequately recognize family members of cancer patients as potential links in improving health outcomes and care (Epstein \& Street, 2007). Pediatric oncology providers need better communication with their patients and families to thoroughly understand the human experience associated with childhood cancer from the perspective of the patient, parents, and well family members. Symptoms may be better recognized and managed by the clinician seeking and trying to understand the health experience from the perspective of the child with cancer and his or her family. This enhanced understanding of the health experience may reveal symptoms, such as fatigue, that the patient and families feel are inevitable and have not discussed with the health care provider. Patient centered communication is imperative to providing excellent care and improving the patient's day-to-day quality of life. 


\section{Education}

Childhood cancer-related fatigue is an often a neglected symptom in clinical practice (Yilmaz et al., 2010). This neglect may be a reflection of health care providers' lack of formal education. The majority of healthcare providers report never receiving formal training related to childhood cancer-related fatigue (Gibson et al., 2006; Yilmaz et al.); however, 75\% report they would benefit from further education about childhood cancer-related fatigue (Yilmaz et al., p. 333). The lack of formal childhood cancer-related fatigue education limits the healthcare providers understanding of assessing, recognizing, managing, and evaluating the symptom. Healthcare providers neglect in recognizing and managing fatigue conveys to the parents that fatigue is not a priority. All pediatric oncology nurses should receive formal education of childhood cancer-related fatigue during initial chemotherapy certification and review programs. This formal education of childhood cancer related fatigue may assist pediatric oncology nurses in recognizing, managing, and evaluating fatigue in children with cancer and improving the child's day-to-day quality of life.

The National Cancer Institute recognizes communication among health care providers, patients, and families as an integral component of providing high quality cancer care (Epstein \& Street, 2007). Patient-centered and family focused communication needs to be central to the education of all health care professionals, including nursing and medical curricula. Patientcentered and family focused communication theory and techniques should be introduced early and throughout education in order to become an inherent part of the clinician's developing practice. Improving communication among clinicians, families of children with cancer, and children with cancer will support assessment, diagnosis, planning, intervention development, and 
evaluation of everyday experiences and symptoms that the child and family may be experiencing.

\section{Research}

The findings of this study suggest differences exist in how parents, researchers and clinicians talk about cancer-related fatigue and make sense of how the symptom shapes everyday quality of life. The investigator of this study discussed several plausible explanations of this discontinuity, including: (a) parents may have difficulty "deconstructing" their child's symptom experiences, (b) parents develop a "new normal" for their child with cancer, and (c) fatigue and/or quality of life represent something much different to parents than the researcher. Additional research in each of these areas may provide a better understanding of the parent's description and interpretation of how everyday symptoms from cancer and cancer treatment, including fatigue, shape their child's day-to-day life. Gaining a better understanding of how parents interpret the construct of childhood cancer-related fatigue would be beneficial in communicating with parents of children with cancer.

As previously discussed, clinicians do not adequately recognize family members of cancer patients as potential links in improving health outcomes and care (Epstein \& Street, 2007). Parents are experts of caring for their children with cancer, and know what is normal and abnormal for their child with cancer. Unlike health care professionals who get only a "snap shot" view of the child in an outpatient setting, a parent sees the "whole picture" by living and caring for their child every day. However, this study supports that parents' concerns are often discounted or not heard by pediatric oncology healthcare professionals. This is a significant finding that deserves further attention to better understand what is hindering the communication between healthcare professionals and parents of children with cancer. The professional culture of 
pediatric oncology at the facility where this study was conducted is such that professionals are deemed as the experts in cancer care and priorities are determined by the science of cancer treatment and cure. Within this context, the acknowledged "experts in cancer care" might discount what parents say, especially if parents are from lower socioeconomic status, less educated, and/or less articulate than the professionals. A study aimed at understanding sociocultural contexts, processes, and meanings of formal care of children with cancer and their families may yield insight into the major findings of this study.

Parents $(n=2)$ of very young children (2 years and under) described unique characteristics of fatigue. Parents recounted times when their toddler would "go, go, go, and crash" from exhaustion. Parents of these very young children also described more emotional aspects of dayto-day life, describing their toddler with cancer as angry and aggressive. Very few studies of fatigue have included children under the age of six, and this is the first study to include children under the age of two. As children in the age group typically do not have the linguistic capability to describe what they are feeling, parent interviews could be augmented by observational studies of these very young children to provide depth to our understanding of fatigue in very young children with cancer and how the symptom impacts their day-to-day life. Such studies may glean important information about the causes of and primary and secondary prevention strategies to ameliorate cancer-related fatigue among toddlers.

Participants in this study clearly identified cancer treatment as the source of many problems. Chemotherapy, hospitalization, procedures, appointments, and long commutes for treatment were associated with making the child feel sick and causing the child to be tired, moody, nauseous, and achy. Most parents did not interpret the child as having fatigue but felt their children were experiencing side effects of therapy that was making them physically unable 
to "do." Steroids were repeatedly identified for causing major side effects and interpreted as "one of the worse things." Parents described contrary effects of steroids on their child's energy level. Some parents reported their child was very hyperactive on steroids, at times uncontrollable. Other parents reported their child as feeling tired and not wanting to do much when taking steroids. Parents recurrently and voluntarily spoke about the negative side effects of steroids and the impact the side effects from steroids had on their child's day-to-day quality of life. Additional research is needed to better understand the impact of steroids on energy level and how the change in energy level may impact the day-to-day quality of life of a child with cancer.

Methodological considerations were raised during the recruitment phase of this study. As previously mentioned recruitment of participants took one year, much longer than anticipated. Adjustments in recruitment procedures were made in an effort to obtain an adequate sample. Two critical adjustments were made: (a) participants did not need to report fatigue to be included in the study, and (b) the investigator had more of a "presence" in the recruitment setting. Both of these changes yielded very positive results in obtaining an adequate sample. By far, the most beneficial change was the investigator being present when the study was introduced. At that time participants could verbalize their interest in the study and the investigator could speak with them; eliminating the need for participants to save contact information and make a call. Several participants commented that they recalled reading the advertisement flyers and were provided the information about the study, but making a phone was just "one more thing they had to do." This reinforces the need for flexibility in pediatric oncology research. It is necessary that individuals or teams wishing to conduct pediatric oncology research keep participants' needs in mind and be willing to adjust to their participants needs as necessary. 
Strengths and Limitations

\section{Strengths}

One of the major strengths of this study was gaining perspectives from diverse caregivers of children with cancer. The varied caregiver perspective included mothers (6), fathers (2), married parents (2), and a non-custodial father and custodial paternal grandfather of a child with cancer. Additionally, the participants of this study cared for children of diverse developmental levels. The parents of this study cared for toddlers (3), preschoolers (3), younger school-age (2), and older school-age (3) children. This varied caregiver perspective and diverse developmental levels of the children supported in identifying common patterns present across variations.

Another strength of this study was that similar themes and categories were uncovered across the diverse sample. No new themes or categories emerged after the first 9 interviews or the additional two interviews that were done. Moreover, an audit trail was maintained outlining the systematic approach the investigator took that was consistent with conventional content analysis, using the research question, the concept of fatigue, and domains of quality of life as an anchor throughout category and thematic development

\section{Limitations}

Limitations of this study are homogenous ethnic and geographic nature of this sample. Participants of this study represent parents of children who are receiving care from the same team of healthcare providers in a specific setting thereby limiting the transferability of these findings to similar settings. As discussed in previous sections, healthcare providers neglect in recognizing and managing fatigue may convey to parents that fatigue is not a priority. Therefore, healthcare providers' attention, or lack of attention, to fatigue may “bias" parents understanding of fatigue. This may have contributed to the lack of recognition of fatigue in the majority of 
parents in this study. Additionally, all participants in this study were Caucasian. This limits the understanding of ethnic or cultural influences of parents' description and interpretation of how fatigue from cancer impacts their child's everyday life. The limited ethnic and geographic diversity may have influenced how parents framed the symptom of fatigue and impacted parents descriptions and interpretation of how fatigue shaped day-to-day quality of life.

\section{Conclusion}

The purpose of this qualitative descriptive study was to gain the parents' description and interpretation of how cancer-related fatigue shapes their child's (1-12 years of age) day-to-day quality of life. Within this chapter the investigator related the findings to relevant theories and other research findings, offered implications of the findings to nursing practice, teaching and research, and discussed strengths and limitations of this study.

The findings of this study indicate that parents and professionals think and talk about fatigue and its meaning quite differently and at times this miscommunication precluded timely diagnosis and treatment of cancer and associated complications. This study offers new insights into how health professionals in this study's setting might improve care through better communication and assessment of fatigue and by seeking an understanding of its meaning to children living with cancer and their parents. Additionally, this study sheds light on the experience of cancer-related fatigue in very young children, although the number of younger children in this study was small. To the investigator's knowledge, this is the first study to report a go, go, go and crash phenomenon that appears to be exclusive to the toddler age group. Many health professionals may consider this phenomenon to be typical toddler behavior. Yet, in this study, it was not normal and parents felt as though their concerns were not heard. As a result of this miscommunication, the diagnosis of cancer and the treatment of serious complications of 
cancer were delayed. These findings underscore the importance of eliciting parents' perspectives on cancer-related fatigue in behavioral terms and comparing life before and after cancer in order to more effectively assess and address the physical and psychosocial needs of the child with cancer and their parents. 


\section{References}

American Cancer Society. Cancer facts and figures. Retrieved March 12, 2013, from http://www.cancer.org/acs/groups/content/@epidemiologysurveilance/documents/docum ent/acspc-036845.pdf

American Cancer Society. Treating nodular lymphocyte predominant Hodgkin disease (NLPHD). Retrieved March 12, 2013, from http://www.cancer.org/cancer/hodgkindisease/detailedguide/hodgkin-disease-treatingnlphd

Chiang, Y., Yeh, C., Wang, K., \& Yang, C. (2009). The experience of cancer-related fatigue in Taiwanese children. European Journal of Cancer Care, 18(1), 43-49.

Davies, B., Whitsett, S. F., Bruce, A., \& McCarthy, P. (2002). A typology of fatigue in children with cancer. Journal of Pediatric Oncology Nursing, 19(1), 12-21.

Docherty, S., \& Sandelowski, M. (1999). Focus on qualitative methods: interviewing children. Research in Nursing \& Health, 22(2), 177-185.

Downe-Wamboldt, B. (1992). Content analysis: method, applications, and issues. Health Care for Women International, 13(3), 313-321.

Eiser, C. \& Morse, R. (2001). Can parents rate their child's health-related quality of life? Results of a systematic review. Quality of life Research, 10, 347-357.

Ekti Genc, R., \& Conk, Z. (2008). Impact of effective nursing interventions to the fatigue syndrome in children who receive chemotherapy. Cancer Nursing, 31(4), 312-317.

Elo, S., \& Kyngas, H. (2008). The qualitative content analysis process. Journal of Advanced Nursing, 62(1), 107-115. 
Enskar, K., \& von Essen, L. (2008). Physical problems and psychosocial function in children with cancer. Paediatric Nursing, 20(3), 37-41.

Epstein RM, Street RL Jr. Patient-Centered Communication in Cancer Care: Promoting Healing and Reducing Suffering. National Cancer Institute, NIH Publication No. 07-6225. Bethesda, MD, 2007.http://outcomes.cancer.gov/areas/pcc/communication/pccm_ch6.pdf

Fernandez, V. M. \& Fernandez, K. M. (2011, November). Transcultural nursing: basic concepts \& case studies. Retrieved from http://www.culturediversity.org/provc.htm

Garrard, J. (2007). Health sciences literature review made easy: The matrix method. Sudbury, MA: Jones \& Bartlett Publishers, Inc.

Gedaly-Duff, V., Lee, K. A., Nail, L. M., Nicholson, H. S., \& Johnson, K. P. (2006). Pain, sleep disturbance, and fatigue in children with leukemia and their parents: a pilot study. Oncology Nursing Forum, 33(3), 641-646.

Gibson, F., Edwards, J., Sepion, B., \& Richardson, A. (2006). Cancer-related fatigue in children and young people: survey of healthcare professionals' knowledge and attitudes. European Journal of Oncology Nursing, 10(4), 311-316.

Gibson, F., Garnett, M., Richardson, A., Edwards, J., \& Sepion, B. (2005). Heavy to carry: a survey of parents' and healthcare professionals' perceptions of cancer-related fatigue in children and young people. Cancer Nursing, 28(1), 27-35.

Gibson, F., Mulhall, A. B., Richardson, A., Edwards, J. L., Ream, E., \& Sepion, B. J. (2005). A phenomenologic study of fatigue in adolescents receiving treatment for cancer. Oncology Nursing Forum, 32(3), 651-660. 
Graneheim, U. H., \& Lundman, B. (2004). Qualitative content analysis in nursing research: concepts, procedures and measures to achieve trustworthiness. Nurse Education Today, 24(2), 105-112.

Hedstrom, M., Haglund, K., Skolin, L., \& von Essen, L. (2003). Distressing events for children and adolescents with cancer: child, parent, and nurse perceptions. Journal of Pediatric Oncology Nursing, 20(3), 120-132.

Hinds, P.S. (2010). Progress in quality of life in children and adolescents with cancer. Seminars in Oncology Nursing,26(1), 18-25.

Hinds, P.S., Burghen, E., Haase, J., \& Phillips, C. (2006). Advances in defining, conceptualizing, and measuring quality of life in pediatric patients with cancer. Oncology of Nursing Forum, 33(1), 23-29.

Hinds, P.S., Gattuso, J.S., Fletcher, A., Baker, E., Coleman, B., Jackson, T., Jacobs-Levine, A., June, D., Rai, S.N., Lensing, S., \& Pui, C. (2004). Quality of life conveyed by pediatric patients with cancer. Quality of Life Research,13, 761-772.

Hinds, P. S., \& Hockenberry-Eaton, M. (2001). Developing a research program on fatigue in children and adolescents diagnosed with cancer. Journal of Pediatric Oncology Nursing, $18(2), 3-12$.

Hinds, P. S., Hockenberry-Eaton, M., Gilger, E., Kline, N., Burleson, C., Bottomley, S., et al. (1999). Comparing patient, parent, and staff descriptions of fatigue in pediatric oncology patients. Cancer Nursing, 22(4), 277-289.

Hinds, P. S., Hockenberry-Eaton, M., Quargneti, A., May, M., Burleson, C., Gilger, E., et al. (1999). Fatigue in 7- to 12-year-old patients with cancer from the staff perspective: an exploratory study. Oncology Nursing Forum, 26(1), 37-45. 
Hinds, P. S., Hockenberry, M., Rai, S. N., Zhang, L., Razzouk, B. I., Cremer, L., et al. (2007). Clinical field testing of an enhanced-activity intervention in hospitalized children with cancer. Journal Of Pain And Symptom Management, 33(6), 686-697.

Hinds, P. S., Hockenberry, M., Rai, S. N., Zhang, L., Razzouk, B. I., McCarthy, K., et al. (2007). Nocturnal awakenings, sleep environment interruptions, and fatigue in hospitalized children with cancer. Oncology Nursing Forum, 34(2), 393-402.

Hinds, P. S., Hockenberry, M., Tong, X., Gattuso, J. S., McCarthy, K., Pui, C., et al. (2007). Validity and reliability of a new instrument to measure cancer-related fatigue in adolescents. Journal of Pain \& Symptom Management, 34(6), 607-618.

Hockenberry-Eaton, M., Hinds, P., O'Neill, J. B., Alcoser, P., Bottomley, S., Kline, N. E., et al. (1999). Developing a conceptual model for fatigue in children... including commentary by Eiser C and Enskar K. European Journal of Oncology Nursing, 3(1), 5-13.

Hockenberry-Eaton, M., \& Hinds, P. S. (2000). Fatigue in children and adolescents with cancer: evolution of a program of study... including commentary by Mock V and Barr RD. Seminars in Oncology Nursing, 16(4), 261-276.

Hockenberry-Eaton, M., Hinds, P. S., Alcoser, P., O'Neill, J. B., Euell, K., Howard, V., et al. (1998). Fatigue in children and adolescents with cancer. Journal of Pediatric Oncology Nursing, 15(3), 172-182.

Hockenberry, M. J., Hinds, P. S., Barrera, P., Bryant, R., Adams-McNeill, J., Hooke, C., et al. (2003). Three instruments to assess fatigue in children with cancer: the child, parent and staff perspectives. Journal of Pain \& Symptom Management, 25(4), 319-328.

Hockenberry, M. J., Hooke, M. C., Gregurich, M., \& McCarthy, K. (2009). Carnitine plasma levels and fatigue in children/adolescents receiving cisplatin, ifosfamide, or doxorubicin. 
Journal Of Pediatric Hematology/Oncology: Official Journal of The American Society of Pediatric Hematology/Oncology, 31(9), 664-669.

Hsieh, H., \& Shannon, S. E. (2005). Three approaches to qualitative content analysis. Qualitative Health Research, 15(9), 1277-1288.

Kortesluoma, R., Hentinen, M., \& Nikkonen, M. (2003). Conducting a qualitative child interview: methodological considerations. Journal of Advanced Nursing, 42(5), 434-441.

Lai, J.-S., Cella, D., Kupst, M. J., Holm, S., Kelly, M. E., Bode, R. K., et al. (2007). Measuring fatigue for children with cancer: development and validation of the pediatric Functional Assessment of Chronic Illness Therapy-Fatigue (pedsFACIT-F). Journal of Pediatric Hematology/Oncology: Official Journal of The American Society of Pediatric Hematology/Oncology, 29(7), 471-479.

Lincoln, Y, S., \& Guba, E, G. (1985). Naturalistic inquiry. Newbury Park: Sage.

Meeske, K., Katz, E. R., Palmer, S. N., Burwinkle, T., \& Varni, J. W. (2004). Parent proxyreported health-related quality of life and fatigue in pediatric patients diagnosed with brain tumors and acute lymphoblastic leukemia. Cancer, 101(9), 2116-2125.

Perdikaris, P., Merkouris, A., Patiraki, E., Papadatou, D., Vasilatou-Kosmidis, H., \& Matziou, V. (2008). Changes in children's fatigue during the course of treatment for paediatric cancer. International Nursing Review, 55(4), 412-419.

Perdikaris, P., Merkouris, A., Patiraki, E., Tsoumakas, K., Vasilatou-Kosmidis, E., \& Matziou, V. (2009). Evaluating cancer related fatigue during treatment according to children's, adolescents' and parents' perspectives in a sample of Greek young patients. European Journal Of Oncology Nursing: The Official Journal Of European Oncology Nursing Society, 13(5), 399-408. 
Ream, E., Gibson, F., Edwards, J., Seption, B., Mulhall, A., \& Richardson, A. (2006).

Experience of fatigue in adolescents living with cancer. Cancer Nursing, 29(4), 317-326.

Sandelowski, M. (1995). Focus on qualitative methods. Qualitative analysis: what it is and how to begin. Research in Nursing \& Health, 18(4), 371-375.

Sandelowski, M. (2000). Focus on research methods. Whatever happened to qualitative description? Research in Nursing \& Health, 23(4), 334-340.

Sandelowski, M. (2010) What's in a name? Qualitative description revisited. Research in Nursing \& Health, 33(1), 77-84.

Thorne, S., Kirkham, S. R., \& MacDonald-Emes, J. (1997). Focus on qualitative methods. Interpretive description: a noncategorical qualitative alternative for developing nursing knowledge. Research in Nursing \& Health, 20(2), 169-177.

Varni, J. W., Burwinkle, T. M., Katz, E. R., Meeske, K., \& Dickinson, P. (2002). The PedsQL in pediatric cancer: reliability and validity of the Pediatric Quality of Life Inventory Generic Core Scales, Multidimensional Fatigue Scale, and Cancer Module. Cancer, 94(7), 20902106.

Whitsett, S. F., Gudmundsdottir, M., Davies, B., McCarthy, P., \& Friedman, D. (2008). Chemotherapy-related fatigue in childhood cancer: correlates, consequences, and coping strategies. Journal of Pediatric Oncology Nursing, 25(2), 86-96.

Woodgate, R. (2000a). Part I: an introduction to conducting qualitative research in children with cancer. Journal of Pediatric Oncology Nursing, 17(4), 192-206.

Woodgate, R. (2000b). Part II: a critical review of qualitative research related to children's experiences with cancer. Journal of Pediatric Oncology Nursing, 17(4), 207-228. 
Woodgate, R., Degner, L., \& Yanofsky, R. (2003). A different perspective to approaching cancer symptoms in children. Journal of Pain \& Symptom Management, 26(3), 800-817.

Woodgate, R. \& Degner, L. (2003). Expectations and beliefs about children's cancer symptoms: perspectives of children with cancer. Oncology Nursing Forum, 30(3) 479491.

Woodgate, R. \& Degner, L. Cancer symptom transition periods of children and families. Journal of Advanced Nursing, 46(4), 358-368.

Hockenberry, M., Wilson D., \& Winkelstein. (2011). Wong's nursing care of infants and children ( $\left.9^{\text {th }} e d.\right)$. Philadelphia: Mosby.

Wu, M., Hsu, L., Zhang, B., Shen, N., Lu, H., \& Li, S. (2010). The experiences of cancer-related fatigue among Chinese children with leukaemia: a phenomenological study. International Journal of Nursing Studies, 47, 49-59.

Yeh, C. H., Chiang, Y. C., Lin, L., Yang, C. P., Chien, L. C., Weaver, M. A., et al. (2008).

Clinical factors associated with fatigue over time in paediatric oncology patients receiving chemotherapy. British Journal of Cancer, 99(1), 23-29.

Yilmaz, H. B., Tas, F., Muslu, G. K., Basbakkal, K., \& Kantar, M. (2010). Health professionals' estimation of cancer-related fatigue in children. Journal of Pediatric Oncology Nursing, 27(6), 330-337. 
Appendix A

Detailed Description of Studies Referenced in Empirical Section

\begin{tabular}{|c|c|c|c|c|c|c|}
\hline Author \& Date & Article & Purpose & Design & Procedures & $\mathbf{N}$ & Main Finding(s) \\
\hline $\begin{array}{l}\text { Hockenberry- } \\
\text { Eaton, Hinds, } \\
\text { Alcoser, O'Neill, } \\
\text { Euell, Howard, } \\
\text { Gattuso, \& Taylor } \\
\text { (1998) }\end{array}$ & $\begin{array}{l}\text { Fatigue in } \\
\text { children and } \\
\text { adolescents with } \\
\text { cancer }\end{array}$ & $\begin{array}{l}\text { Define and describe } \\
\text { fatigue experience }\end{array}$ & Qualitative & Focus Group & $\begin{array}{l}29 \text { children } \\
\text { and teens } \\
14 \text { children } \\
15 \text { teens }\end{array}$ & $\begin{array}{l}\text { Physical and mental } \\
\text { symptoms described } \\
\text { Developmental level } \\
\text { varies description }\end{array}$ \\
\hline $\begin{array}{l}\text { Hinds, } \\
\text { Hockenberry- } \\
\text { Eaton, Quargnenti, } \\
\text { May, Burleson, } \\
\text { Gilger, Randall \& } \\
\text { O'Neill (1999) }\end{array}$ & $\begin{array}{l}\text { Fatigue in 7-12- } \\
\text { year-old patients } \\
\text { with cancer from } \\
\text { the staff } \\
\text { perspective: an } \\
\text { exploratory study }\end{array}$ & $\begin{array}{l}\text { Explore Staff } \\
\text { Perspective of } \\
\text { characteristics, } \\
\text { causes, and } \\
\text { alleviating factors of } \\
\text { fatigue in school-age } \\
\text { children }\end{array}$ & Qualitative & Focus Group & $\begin{array}{l}38 \text { staff } \\
\text { members }\end{array}$ & $\begin{array}{l}\text { Fatigue is perceived } \\
\text { as debilitating } \\
\text { Fatigue defined } \\
\text { Causes and } \\
\text { alleviating factors } \\
\text { identified }\end{array}$ \\
\hline $\begin{array}{l}\text { Hinds, } \\
\text { Hockenberry- } \\
\text { Eaton, Gilger, Kline, } \\
\text { Burleson, } \\
\text { Bottomley, \& } \\
\text { Quargnenti (1999) }\end{array}$ & $\begin{array}{l}\text { Comparing } \\
\text { patient, parent, } \\
\text { and staff } \\
\text { descriptions of } \\
\text { fatigue in } \\
\text { pediatric } \\
\text { oncology patients }\end{array}$ & $\begin{array}{l}\text { Describe three } \\
\text { perspectives of } \\
\text { fatigue. Define and } \\
\text { identify causes and } \\
\text { alleviating factors of } \\
\text { fatigue }\end{array}$ & Qualitative & Focus Group & $\begin{array}{l}29 \text { children and } \\
\text { teens } \\
38 \text { staff } \\
31 \text { parents }\end{array}$ & $\begin{array}{l}\text { Children, } \\
\text { adolescents, parents, } \\
\text { and staff all describe } \\
\text { fatigue differently }\end{array}$ \\
\hline $\begin{array}{l}\text { Hockenberry- } \\
\text { Eaton, Hinds, } \\
\text { O'Neill, Alcoser, } \\
\text { Bottomley, Kline, } \\
\text { Euell, Howard, \& } \\
\text { Gattuso (1999) }\end{array}$ & $\begin{array}{l}\text { Developing a } \\
\text { conceptual model } \\
\text { for fatigue in } \\
\text { children }\end{array}$ & $\begin{array}{l}\text { Develop a conceptual } \\
\text { definition of fatigue } \\
\text { in children, ages 7-12 } \\
\text { years, with cancer }\end{array}$ & Qualitative & Focus Group & 14 children & $\begin{array}{l}\text { Conceptual definition } \\
\text { and model developed }\end{array}$ \\
\hline
\end{tabular}




\begin{tabular}{|c|c|c|c|c|c|c|}
\hline Author \& Date & Article & Purpose & Design & Procedures & $\mathbf{N}$ & Main Finding(s) \\
\hline $\begin{array}{l}\text { Davies, } \\
\text { Whitsett, Bruce, } \\
\text { McCarthy } \\
\text { (2002) }\end{array}$ & $\begin{array}{l}\text { A typology of } \\
\text { fatigue in children } \\
\text { with cancer }\end{array}$ & $\begin{array}{l}\text { Do gain a detailed } \\
\text { description of } \\
\text { fatigue in children } \\
\text { with cancer }\end{array}$ & $\begin{array}{l}\text { Qualitative } \\
\text { Grounded theory }\end{array}$ & $\begin{array}{l}\text { Separate interviews of } \\
\text { child and parent }\end{array}$ & $\begin{array}{l}13 \text { children (5- } \\
15 \text { years of } \\
\text { age) } \\
12 \text { adult }\end{array}$ & $\begin{array}{l}\text { Fatigue conveyed } \\
\text { in terms of } \\
\text { energy } \\
\text { Three types of } \\
\text { fatigue were } \\
\text { identified }\end{array}$ \\
\hline $\begin{array}{l}\text { Woodgate, } \\
\text { Degner,\& } \\
\text { Yanofsky (2003) }\end{array}$ & $\begin{array}{l}\text { A different } \\
\text { perspective to } \\
\text { approaching } \\
\text { cancer symptoms } \\
\text { in children }\end{array}$ & $\begin{array}{l}\text { Describing the } \\
\text { "cancer symptom } \\
\text { course from the } \\
\text { perspectives of } \\
\text { children and their } \\
\text { families" (p. 802) }\end{array}$ & $\begin{array}{l}\text { Qualitative } \\
\text { Longitudinal }\end{array}$ & $\begin{array}{l}\text { Individual and family } \\
\text { Interviews }\end{array}$ & $\begin{array}{l}39 \text { children ( } 4 \\
1 / 2-18 \text { years of } \\
\text { age) and their } \\
\text { families- } \\
\text { parents and } \\
\text { siblings }\end{array}$ & $\begin{array}{l}\text { Eight feeling } \\
\text { states identified } \\
\text { Central to Fatigue } \\
: \\
\text { "I am wiped } \\
\text { out...my body is } \\
\text { just too tired for } \\
\text { me to care" (p. } \\
810 \text { ) }\end{array}$ \\
\hline $\begin{array}{l}\text { Meeske, Katz, } \\
\text { Palmer, } \\
\text { Burwinkle, \& } \\
\text { Varni (2004) }\end{array}$ & $\begin{array}{l}\text { Parent proxy- } \\
\text { reported health } \\
\text { related quality of life } \\
\text { and fatigue in } \\
\text { pediatric patients } \\
\text { diagnosed with brain } \\
\text { tumors and ALL } \\
\end{array}$ & $\begin{array}{l}\text { To compare } \\
\text { HRQOL between } \\
\text { patients with ALL } \\
\text { and brain tumors }\end{array}$ & $\begin{array}{l}\text { Quantitative } \\
\text { Descriptive }\end{array}$ & $\begin{array}{l}\text { PedsQL , generic Core } \\
\text { Scales, Acute Cancer } \\
\text { Module, and } \\
\text { Multidimensional } \\
\text { Fatigue Scales }\end{array}$ & $\begin{array}{l}256 \text { parents of } \\
\text { children ( } 2-18 \\
\text { years of age) } \\
\text { with ALL or } \\
\text { brain tumors }\end{array}$ & $\begin{array}{l}\text { Pattern of fatigue } \\
\text { differs in patients } \\
\text { with brain tumors }\end{array}$ \\
\hline $\begin{array}{l}\text { Gibson, } \\
\text { Edwards, } \\
\text { Sepion, \& } \\
\text { Richardson } \\
\text { (2005) }\end{array}$ & $\begin{array}{l}\text { Cancer-related } \\
\text { fatigue in children } \\
\text { and young people: } \\
\text { survey of healthcare } \\
\text { professionals' } \\
\text { knowledge and } \\
\text { attitudes }\end{array}$ & $\begin{array}{l}\text { Assess knowledge } \\
\text { of cancer-related } \\
\text { fatigue in } \\
\text { healthcare } \\
\text { professionals }\end{array}$ & $\begin{array}{l}\text { Quantitative } \\
\text { Descriptive }\end{array}$ & $\begin{array}{l}19 \text { item Questionnaire } \\
\text { Distributed at The } \\
\text { (2001) International } \\
\text { Society of Pediatric } \\
\text { Oncology conference }\end{array}$ & $\begin{array}{l}60 \\
46 \text { nurses } \\
10 \text { physicians } \\
4 \text { other HCP }\end{array}$ & $\begin{array}{l}48 \% \text { did not } \\
\text { assess fatigue } \\
95 \% \text { lacked } \\
\text { formal education } \\
r / t \text { fatigue (p.313) }\end{array}$ \\
\hline
\end{tabular}




\begin{tabular}{|c|c|c|c|c|c|c|}
\hline Author \& Date & Article & Purpose & Design & Procedures & $\mathbf{N}$ & Main Finding(s) \\
\hline $\begin{array}{l}\text { Gibson, Garnett, } \\
\text { Richardson, } \\
\text { Edwards, \& Sepion } \\
\text { (2005) }\end{array}$ & $\begin{array}{l}\text { Heavy to Carry. A } \\
\text { survey of parents' } \\
\text { and healthcare } \\
\text { professionals' } \\
\text { perceptions of } \\
\text { cancer-related } \\
\text { fatigue in children } \\
\text { and young people }\end{array}$ & $\begin{array}{l}\text { Gain parents and } \\
\text { healthcare } \\
\text { professionals } \\
\text { perspective of } \\
\text { cancer -related } \\
\text { fatigue and } \\
\text { examine its impact } \\
\text { on quality of life }\end{array}$ & $\begin{array}{l}\text { Quantitative } \\
\text { Descriptive }\end{array}$ & $\begin{array}{l}\text { Modified version of } \\
\text { fatigue subscale from } \\
\text { the Functional } \\
\text { Assessment of Cancer } \\
\text { Therapy- Fatigue } \\
\text { (FACT-F) } \\
\text { A questionnaire } \\
\text { adapted from adult } \\
\text { oncology research }\end{array}$ & $\begin{array}{l}95 \text { parents } \\
\text { of a child } \\
\text { ( } 2-18 \text { years } \\
\text { of age) with } \\
\text { cancer } \\
235 \mathrm{HCP}\end{array}$ & $\begin{array}{l}\text { Significant } \\
\text { problem, but } \\
\text { other symptoms } \\
\text { better recognized }\end{array}$ \\
\hline $\begin{array}{l}\text { Hinds, } \\
\text { Hockenberry, Rai, } \\
\text { Zhang, Razzouk, } \\
\text { Cremer, McCarthy, } \\
\text { Rodriguez-Galindo } \\
\text { (2007) }\end{array}$ & $\begin{array}{l}\text { Clinical field testing } \\
\text { of an enhanced- } \\
\text { activity } \\
\text { intervention in } \\
\text { hospitalized } \\
\text { children with } \\
\text { cancer }\end{array}$ & $\begin{array}{l}\text { Assess feasibility of } \\
\text { an enhanced } \\
\text { physical activity } \\
\text { (EPA) intervention } \\
\text { in hospitalized } \\
\text { children }\end{array}$ & $\begin{array}{l}\text { Quantitative } \\
\text { Quasi } \\
\text { Pilot }\end{array}$ & $\begin{array}{l}\text { EPA- pedaling } \\
\text { stationary bike for } 30 \\
\text { minutes, two } \\
\text { times/day for 2-4 } \\
\text { days of } \\
\text { hospitalization } \\
\text { Sleep diary } \\
\text { Wrist actigraph } \\
\text { CFS(child fatigue } \\
\text { scale), PFS (parent } \\
\text { fatigue scale), SFS } \\
\text { (staff fatigue scale), } \\
\text { FS-A (adolescent } \\
\text { fatigue scale) } \\
\text { Data r/t Medication, } \\
\text { H\&H }\end{array}$ & $\begin{array}{l}29 \\
\text { ( } 7-18 \text { years } \\
\text { of age) }\end{array}$ & $\begin{array}{l}\text { EPA deemed } \\
\text { feasible }\end{array}$ \\
\hline
\end{tabular}




\begin{tabular}{|c|c|c|c|c|c|c|}
\hline Author \& Date & Article & Purpose & Design & Procedures & $\mathbf{N}$ & Main Finding(s) \\
\hline $\begin{array}{l}\text { Hinds, } \\
\text { Hockenberry, } \\
\text { Rai, Zhang, } \\
\text { Razzouk, } \\
\text { McCarthy, } \\
\text { Cremer, \& } \\
\text { Rodriguez- } \\
\text { Galindo (2007) }\end{array}$ & $\begin{array}{l}\text { Nocturnal } \\
\text { awakenings, sleep } \\
\text { environment } \\
\text { interruptions, and } \\
\text { fatigue in } \\
\text { hospitalized } \\
\text { children with } \\
\text { cancer }\end{array}$ & $\begin{array}{l}\text { Describe and assess } \\
\text { relationship of } \\
\text { nocturnal } \\
\text { awakenings, } \\
\text { interruptions, sleep } \\
\text { duration, and } \\
\text { fatigue in } \\
\text { hospitalized } \\
\text { children and } \\
\text { adolescents. }\end{array}$ & Quantitative & $\begin{array}{l}\text { Actigraphy } \\
\text { CFS, PFS, SFS } \\
\text { Sleep diary } \\
\text { Room entry checklist } \\
\text { Blood samples }\end{array}$ & $\begin{array}{l}29 \text { children } \\
\text { ( } 7-18 \text { years of } \\
\text { age) }\end{array}$ & $\begin{array}{l}\text { Supports } \\
\text { relationship } \\
\text { between sleep } \\
\text { quality and } \\
\text { hospital-related } \\
\text { fatigue }\end{array}$ \\
\hline $\begin{array}{l}\text { Whitsett, } \\
\text { Gudmun } \\
\text { dsdottir, Davies, } \\
\text { McCarthy, } \\
\text { Friedman (2008) }\end{array}$ & $\begin{array}{l}\text { Chemotherapy- } \\
\text { related fatigue in } \\
\text { childhood cancer: } \\
\text { correlates, } \\
\text { consequences, and } \\
\text { coping strategies }\end{array}$ & $\begin{array}{l}\text { Examine } \\
\text { experience of } \\
\text { chemotherapy- } \\
\text { related fatigue in } \\
\text { children newly } \\
\text { diagnosed with } \\
\text { cancer }\end{array}$ & Mixed Method & $\begin{array}{l}\text { Parent interviews } \\
\text { FS-A, PFS,CFS } \\
\text { Center for } \\
\text { Epidemiological } \\
\text { Studies Depression } \\
\text { Scale (CES-D) } \\
\text { H\&H }\end{array}$ & $\begin{array}{l}12 \text { children } \\
\text { ( } 7-17 \text { years of } \\
\text { age) and their } \\
\text { parents }\end{array}$ & $\begin{array}{l}\text { High correlation } \\
\text { between fatigue } \\
\text { and depression } \\
\text { "Suggest } \\
\text { distinguishable } \\
\text { despite frequent } \\
\text { co-occurrence" ( } p \text {. } \\
93 \text { ) }\end{array}$ \\
\hline $\begin{array}{l}\text { Genc \& Conk } \\
(2008)\end{array}$ & $\begin{array}{l}\text { Impact of effective } \\
\text { nursing } \\
\text { interventions to the } \\
\text { fatigue syndrome in } \\
\text { children who } \\
\text { receive } \\
\text { chemotherapy }\end{array}$ & $\begin{array}{l}\text { To assess impact of } \\
\text { nursing } \\
\text { interventions on } \\
\text { decreasing fatigue }\end{array}$ & Quantitative & $\begin{array}{l}\text { Experimental - } \\
\text { received education } \\
\text { about fatigue } \\
\text { Control- routine } \\
\text { nursing care } \\
\text { PFS,CFS }\end{array}$ & $\begin{array}{l}60 \text { children } \\
\text { ( } 7-12 \text { years of } \\
\text { age) }\end{array}$ & $\begin{array}{l}\text { Statistically } \\
\text { significant } \\
\text { difference in lower } \\
\text { fatigue scores in } \\
\text { experimental } \\
\text { group }\end{array}$ \\
\hline
\end{tabular}




\begin{tabular}{|c|c|c|c|c|c|c|}
\hline Author \& Date & Article & Purpose & Design & Procedures & $\mathbf{N}$ & Main Finding(s) \\
\hline $\begin{array}{l}\text { Perdikaris, } \\
\text { Merkouris, } \\
\text { Patiraki, } \\
\text { Papadatou, } \\
\text { Vasilatou- } \\
\text { Kosmidis, } \\
\text { Matziou (2008) }\end{array}$ & $\begin{array}{l}\text { Changes in } \\
\text { children's fatigue } \\
\text { during the course of } \\
\text { treatment for } \\
\text { pediatric cancer }\end{array}$ & $\begin{array}{l}\text { To assess changes } \\
\text { in fatigue scores } \\
\text { during cancer } \\
\text { treatment and } \\
\text { describe possible } \\
\text { cause of fatigue }\end{array}$ & Quantitative & $\begin{array}{l}\text { CFS administered at } \\
\text { the beginning, middle } \\
\text { and end of treatment } \\
\text { protocol }\end{array}$ & $\begin{array}{l}40 \text { children } \\
\text { (ages } 7-12 \\
\text { years) }\end{array}$ & $\begin{array}{l}\text { Treatment } \\
\text { increased fatigue } \\
\text { scores } \\
\text { Procedures and } \\
\text { hospital } \\
\text { environment } \\
\text { identified as } \\
\text { causes }\end{array}$ \\
\hline $\begin{array}{l}\text { Chiang, Yeh, } \\
\text { Wang, \& Yang } \\
\text { (2008) }\end{array}$ & $\begin{array}{l}\text { The experience of } \\
\text { cancer-related } \\
\text { fatigue in } \\
\text { Taiwanese children }\end{array}$ & $\begin{array}{l}\text { Describe the } \\
\text { experience of } \\
\text { cancer-related } \\
\text { fatigue in } \\
\text { Taiwanese children }\end{array}$ & Qualitative & Interviews & $\begin{array}{l}17 \text { children } \\
\text { ( } 7-18 \text { years of } \\
\text { age) }\end{array}$ & $\begin{array}{l}\text { Identified three } \\
\text { age groups } 7-9 \\
\text { years, } 10-12 \text { years, } \\
\text { and } 13-18 \\
\text { Description of } \\
\text { fatigue differed } \\
\text { depending on age }\end{array}$ \\
\hline $\begin{array}{l}\text { Yeh, Chiang, } \\
\text { Yang, Chien, } \\
\text { Weaver, Chuang } \\
\text { (2008) }\end{array}$ & $\begin{array}{l}\text { Clinical factors } \\
\text { associated with } \\
\text { fatigue over time in } \\
\text { pediatric oncology } \\
\text { patients receiving } \\
\text { chemotherapy }\end{array}$ & $\begin{array}{l}\text { Investigate } \\
\text { relationship } \\
\text { between clinical } \\
\text { factors and fatigue } \\
\text { patterns before } \\
\text { and } 10 \text { days } \\
\text { following the } \\
\text { beginning of new } \\
\text { round of } \\
\text { chemotherapy }\end{array}$ & Quantitative & $\begin{array}{l}\text { PedsQL } \\
\text { Multidimensional } \\
\text { Fatigue Scale } \\
\text { PFS } \\
\text { Demographic data }\end{array}$ & $\begin{array}{l}48 \text { Children } \\
\text { (ages } 7-12 \\
\text { years) and } \\
\text { their parents }\end{array}$ & $\begin{array}{l}\text { Children } \\
\text { experience more } \\
\text { fatigue during the } \\
\text { first few days of a } \\
\text { new round of } \\
\text { chemotherapy } \\
\text { Steroids and } \\
\text { hemoglobin level } \\
\text { associated with } \\
\text { higher fatigue } \\
\text { scores }\end{array}$ \\
\hline
\end{tabular}




\begin{tabular}{|c|c|c|c|c|c|c|}
\hline Author \& Date & Article & Purpose & Design & Procedures & $\mathbf{N}$ & Main Finding(s) \\
\hline $\begin{array}{l}\text { Perdikaris, } \\
\text { Merkouris, } \\
\text { Patiraki, } \\
\text { Tsoumakas, } \\
\text { Vasilatou- } \\
\text { Kosmidis, \& } \\
\text { Matziou (2009) }\end{array}$ & $\begin{array}{l}\text { Evaluating cancer } \\
\text { related fatigue } \\
\text { during treatment } \\
\text { according to } \\
\text { children's } \\
\text { adolescents' and } \\
\text { parents' } \\
\text { perspectives in a } \\
\text { sample of Greek } \\
\text { young patients. }\end{array}$ & $\begin{array}{l}\text { Assess changes in } \\
\text { fatigue scores } \\
\text { during cancer } \\
\text { treatment }\end{array}$ & Quantitative & $\begin{array}{l}\text { PFS, CFS, FS-A } \\
\text { Administered at the } \\
\text { beginning, middle and } \\
\text { end of each } \\
\text { treatment protocol }\end{array}$ & $\begin{array}{l}40 \text { children } \\
\text { ( } 7-12 \text { years of } \\
\text { age) and } 29 \\
\text { adolescent } \\
\text { (13-15 years } \\
\text { of age) and } \\
\text { one of their } \\
\text { parents }\end{array}$ & $\begin{array}{l}\text { Fatigue increased } \\
\text { during treatment } \\
\text { Scores highest } \\
\text { between the first } \\
\text { and second } \\
\text { measurement }\end{array}$ \\
\hline $\begin{array}{l}\text { Hockenberry, } \\
\text { Hooke, } \\
\text { Gregurich,\& } \\
\text { McCarthy (2009) }\end{array}$ & $\begin{array}{l}\text { Carnitine plasma } \\
\text { levels and fatigue in } \\
\text { children/adolescents } \\
\text { receiving cisplatin, } \\
\text { ifosfamide, or } \\
\text { doxorubicin }\end{array}$ & $\begin{array}{l}\text { Examine fatigue } \\
\text { and carnitine } \\
\text { before and after } \\
\text { cisplatin, } \\
\text { ifosfamide, or } \\
\text { doxorubicin }\end{array}$ & $\begin{array}{l}\text { Quantitative } \\
\text { correlational }\end{array}$ & $\begin{array}{l}\text { CFS, FS-A } \\
\text { Carnitine plasma } \\
\text { levels }\end{array}$ & $\begin{array}{l}67 \text { children( } 7- \\
18 \text { years of } \\
\text { age) }\end{array}$ & $\begin{array}{l}\text { Carnitine } \\
\text { deficiency } \\
\text { develops during } \\
\text { treatment of these } \\
\text { agents } \\
\text { Patients receiving } \\
\text { Doxorubicin had } \\
\text { more fatigue and } \\
\text { lower carnitine } \\
\text { levels }\end{array}$ \\
\hline
\end{tabular}




\begin{tabular}{|c|c|c|c|c|c|c|}
\hline Author \& Date & Article & Purpose & Design & Procedures & $\mathbf{N}$ & Main Finding(s) \\
\hline $\begin{array}{l}\text { Wu, Hsu, Zhang, } \\
\text { Shen, Lu, \& Li } \\
\text { (2009) }\end{array}$ & $\begin{array}{l}\text { The experience of } \\
\text { cancer-related } \\
\text { fatigue among } \\
\text { Chinese children } \\
\text { with leukemia: a } \\
\text { phenomenological } \\
\text { study }\end{array}$ & $\begin{array}{l}\text { Explore real-life } \\
\text { experiences of } \\
\text { fatigue from the } \\
\text { perspective of } \\
\text { Chines children } \\
\text { with leukemia }\end{array}$ & $\begin{array}{l}\text { Qualitative } \\
\text { Phenomenology }\end{array}$ & Focus group & $\begin{array}{l}14 \text { children } \\
\text { and } \\
\text { adolescent ( } 7- \\
18 \text { year of } \\
\text { age) }\end{array}$ & $\begin{array}{l}\text { Could have } \\
\text { negative effects on } \\
\text { daily lives } \\
\text { Participants } \\
\text { acknowledged } \\
\text { fatigue as a } \\
\text { problem but didn't } \\
\text { report symptom to } \\
\text { HCP or parent }\end{array}$ \\
\hline $\begin{array}{l}\text { Yilmaz, Tas, } \\
\text { Muslu, } \\
\text { Basbakkal, \& } \\
\text { Kantar (2010) }\end{array}$ & $\begin{array}{l}\text { Health } \\
\text { professionals' } \\
\text { estimation of } \\
\text { cancer-related } \\
\text { fatigue in children }\end{array}$ & $\begin{array}{l}\text { Assess HCP } \\
\text { knowledge related } \\
\text { to fatigue in } \\
\text { children with } \\
\text { cancer }\end{array}$ & Quantitative & $\begin{array}{l}\text { Questionnaire } \\
\text { Administered in } 4 \\
\text { pediatric oncology } \\
\text { centers in Turkey }\end{array}$ & $\begin{array}{l}56 \mathrm{HCP} \\
44 \text { nurses } \\
12 \text { physicians }\end{array}$ & $\begin{array}{l}\text { Assessment of } \\
\text { fatigue is by } \\
\text { patient stating } \\
\text { they are tired. } \\
\text { None of the HCP } \\
\text { used an } \\
\text { assessment tool } \\
73 \% \text { never } \\
\text { received education } \\
\text { r/t fatigue }\end{array}$ \\
\hline
\end{tabular}




\section{Appendix B}

West Virginia University School of Nursing

Principal Investigator: Joy Buck, PhD, RN

Associate Professor, Health Promotion and Eastern Division

Phone: 304-264-9202

Email: jbuck@hsc.wvu.edu

\section{Co-Investigator: Tina Antill MBA, MSN, CPNP, RN}

Phone: 724-344-4125

Email: tinaantill@waynesburg.edu

Parents' Perspectives: Observations and Interpretations of Cancer-Related Fatigue and How the Symptom Shapes their Child's Day-to-Day Quality of Life

\section{Interview Information}

INVITATION TO PARTICIPATE: My name is Tina Antill and I am a registered nurse currently working toward a PhD in Nursing at West Virginia University. As part of the dissertation for my PhD I am conducting a research study that involves interviewing parents of children (1-12 years of age) with cancer. You are being invited to participate in this study because you have a child with cancer who is receiving treatment and your child meets the age requirement. This study is being done to see how and if tiredness from cancer and cancer treatment impacts your child's day-to-day life. This information will be used to find ways to help children cope better with being tired during treatment.

PURPOSE: The purpose of this study is to understand how being tired a lot impacts your child's everyday quality of life.

\section{PROCEDURES:}

You will be asked to participate in one recorded interview session, lasting approximately one hour. You can review the questions that will be asked prior to volunteering to participate. The interview will be done at your convenience. You may choose to speak with me in person, by telephone, or video calling. I will review this information with you and answer any questions that you have prior to the interview. If you agree to participate, the interview will be recorded and all information will be kept confidential. You may choose to skip any question that you do not want to answer, stop the interview, or withdraw from the study at any time.

RISKS: There are no anticipated risks to you for participating in this study. 
COSTS AND FINANCIAL RISKS: There are no anticipated financial risks or costs to you for participating in this study. All costs for recording equipment and other expenses will be the responsibility of the research team. The only cost to you will be the time spent during the interview process. Participants will receive a $\$ 20$ gift card in appreciation of participating in the study.

BENEFITS: While you may not gain a direct benefit from participating in this study, it offers you the opportunity to talk about what it is like for your child to live with fatigue from cancer and cancer treatment. As a result, you may benefit from being able to voice your concerns. Additionally, the findings from this study will be used to help children cope with fatigue from cancer and improve their everyday lives.

\section{CONFIDENTIALITY:}

To protect participant confidentiality and privacy, in person interviews will be done in a private room found in the Infusion Center. Telephone interviews will be done in a home office on a private land line phone. Skype will be used to for video calls. Skype video calls are considered a private and secure way to talk. Skype uses many different ways to protect information, including cryptography. Cryptography is a way of changing your protected information so only the person who needs the information is able to read it.

Once the interview is complete, the electronic recording will be catalogued and given a special code that will not contain your name or other identifying information. Only you and the researcher will know your identity. The electronic audio files will be transcribed verbatim and checked for accuracy.

Once accuracy is assured, the audio files will be erased. When transcripts of all the participants have been analyzed, the results may be reported in either oral or written research presentations. No one will know the specific information that you or any of the other participants provided.

DISCLAIMER/WITHDRAWAL: You are not required to enter this research study and your agreement to participate is a voluntary decision. You may refuse to answer any question posed by the interviewer. You understand that you are free to withdraw from this study at any time without penalty or prejudice. You agree that your participation in this study is completely voluntary and that you may withdraw at any time without any negative consequences.

SUBJECT RIGHTS: West Virginia University's IRB acknowledgment of this study is on file. If you wish additional information regarding your rights as a research subject, you may contact the West Virginia University Research Compliance Office by calling 304-293-7073 or emailing irb@mail.wvu.edu

You also understand that if you have any questions pertaining to your participation in this research study, you may contact:

Co-Investigator: Tina Antill MBA, MSN, CPNP, RN

Home number: 724-627-7922

Cell number: 724-344-4125

Email: tantill@waynesburg.edu

Or 
Principal Investigator: Joy Buck, $\mathrm{PhD}, \mathrm{RN}$

Phone: 304-264-9202

Email: jbuck@hsc.wvu.edu 
